\title{
Short Wavelength Inner Filter Technique (SWIFT) in Designing Reactive Fluorescent Molecular Probes
}

\author{
Abhishek Baheti and Arkadi Vigalok* \\ School of Chemistry, Tel Aviv University, Tel Aviv 69978, Israel. Email: \\ avigal@tauex.tau.ac.il
}

\section{Supporting Information}

\section{Contents}

1. General information $\quad$ S2

2. Experimental section $\quad$ S2

3. NMR spectra S6

4. Analyte detection experiments $\quad$ S25

$\begin{array}{ll}\text { 5. Absorption and emission spectra } & \text { S28 }\end{array}$ 


\section{General information}

The synthetic manipulations involving air-sensitive compounds were performed in a nitrogen-filled Innovative Technology glove box. All chemicals were purchased from Sigma Aldrich, Alfa Aesar, Acros, Chem Impex International and used without further purification. All solvents were degassed and stored under high-purity nitrogen and activated $4 \AA$ molecular sieves. All deuterated solvents were stored under high-purity nitrogen on $3 \AA$ molecular sieves. The NMR spectra were recorded on Bruker Avance 400MHz spectrometer. ${ }^{1} \mathrm{H}$ and ${ }^{13} \mathrm{C}$ NMR signals are reported in ppm downfield from TMS. ${ }^{1} \mathrm{H}$ signals are referenced to the residual proton of a deuterated solvent $7.26 \mathrm{ppm}$ for $\mathrm{CDCl}_{3}, 1.94 \mathrm{ppm}$ for $\mathrm{CD}_{3} \mathrm{CN}$ and $2.50 \mathrm{ppm}$ for DMSO- $d{ }^{6} .{ }^{13} \mathrm{C}$ signals are referenced to the solvent signal at $77.36 \mathrm{ppm}$ for $\mathrm{CDCl}_{3}$ and $39.52 \mathrm{ppm}$ for DMSO- $d{ }^{6} .{ }^{19} \mathrm{~F}$ chemical shifts are reported in ppm downfield from $\mathrm{CClF}_{3}$. Mass Spectra were recorded on a VGAutospec M-250 instrument. Absorption and fluorescence spectra were recorded on F2710 fluorescence spectrophotometer (Hitachi) using quartz cuvettes. Visualization was performed with a standard laboratory UV lamp and a four-color (white and RGB) LED flashlight. Abbreviation used: $\mathrm{HSH}=1-\mathrm{Hexanethiol}, \mathrm{CySH}=\mathrm{Cyclohexanethiol}, \mathrm{CysSH}$ $=\mathrm{N}$-(tert-Butoxycarbonyl)-L-cysteine methyl ester, EtSH = 2-Mercaptoethanol.

\section{Experimental section}

Synthesis of Compound 1a.

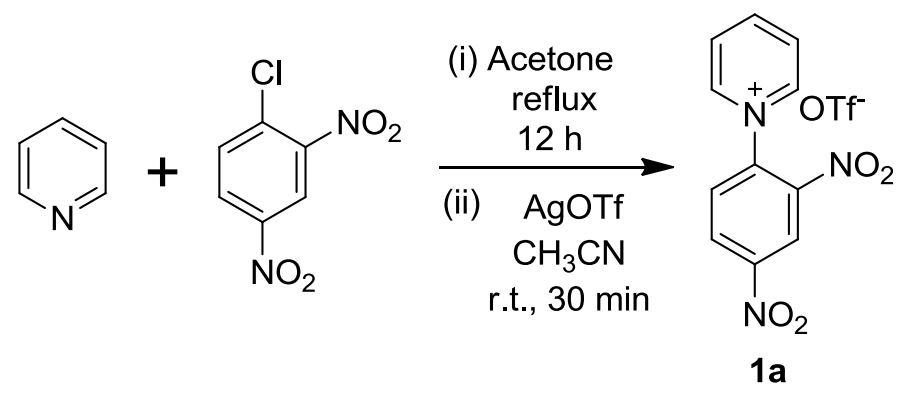

Pyridine $(0.79 \mathrm{~mL}, 10.0 \mathrm{mmol})$ was dissolved in acetone $(10.0 \mathrm{~mL})$ and stirred, while 2,4- dinitrochlorobenzene $(2.02 \mathrm{~g}, 10.0 \mathrm{mmol})$ was added to the reaction mixture. The mixture was heated under reflux for $12 \mathrm{~h}$ and cooled to room temperature. The precipitate produced was filtered under suction and washed with $n$-hexane. Further this solid was 
treated with silver triflate $(2.56 \mathrm{~g}, 10.0 \mathrm{mmol})$ in acetonitrile $(10 \mathrm{~mL})$ at room temperature for 30 minutes. White precipitate formed, which was removed by filtration. The filtrate was evaporated and the obtained solid was washed with diethyl ether. Yield: $3.75 \mathrm{~g}$ (95\%); white solid; ${ }^{1} \mathrm{H}$ NMR (400 MHz, DMSO- $d^{6}$ ): 8.41-8.46 (m, 3H), 8.93-9.00 $(\mathrm{m}, 2 \mathrm{H}), 9.13(\mathrm{~d}, 1 \mathrm{H}, J=2.4 \mathrm{~Hz}), 9.37$ (d, $2 \mathrm{H}, J=9.6 \mathrm{~Hz}) ;{ }^{13} \mathrm{C}$ NMR $(100 \mathrm{M} \mathrm{Hz}$ DMSO$\left.d^{6}\right): 149.5,149.2,146.4,143.4,139.1,132.2,130.6,128.4,121.8$; HRMS (ESI-TOF) $\mathrm{m} / \mathrm{z}:[\mathrm{M}]^{+}$calcd. for $\mathrm{C}_{11} \mathrm{H}_{8} \mathrm{~N}_{3} \mathrm{O}_{4} 246.0509$; found 246.0506 .

Synthesis of Compound $\mathbf{1 b}$.
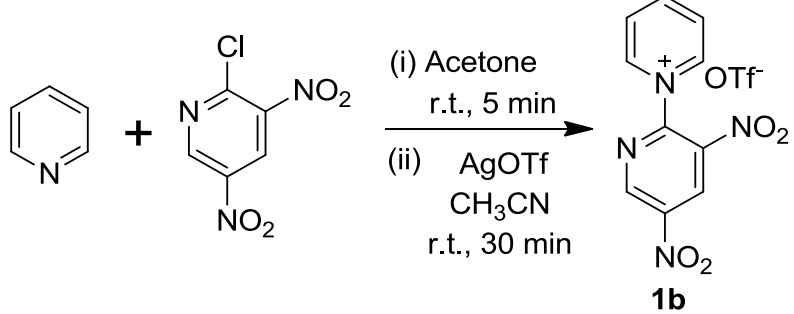

Pyridine $(0.39 \mathrm{~mL}, 5.0 \mathrm{mmol})$ was dissolved in acetone $(10.0 \mathrm{~mL})$ and stirred, while 2chloro-3,5-dinitropyridine $(1.01 \mathrm{~g}, 5.0 \mathrm{mmol})$ was added to the reaction mixture. Within 5 minutes yellow precipitate formed. The precipitate produced was filtered under suction and washed with dichloromethane followed by $n$-hexane. Further this solid was treated with silver triflate $(1.28 \mathrm{~g}, 5.0 \mathrm{mmol})$ in acetonitrile $(5 \mathrm{~mL})$ at room temperature for 30 minutes. White precipitate formed, which was removed by filtration. The filtrate was evaporated and the obtained solid was washed with diethyl ether. Yield: $1.38 \mathrm{~g}(70 \%)$; yellow solid; ${ }^{1} \mathrm{H}$ NMR (400 M Hz, $\mathrm{CD}_{3} \mathrm{CN}$ ): 8.33-8.36 (m, 2H), 8.93 (tt, $2 \mathrm{H}, J=8.0 \mathrm{~Hz}$, $1.6 \mathrm{~Hz}), 9.10(\mathrm{dd}, 2 \mathrm{H}, J=6.8 \mathrm{~Hz}, 1.6 \mathrm{~Hz}), 9.52(\mathrm{~d}, 1 \mathrm{H}, J=2.4 \mathrm{~Hz}), 9.72(\mathrm{~d}, 1 \mathrm{H}, J=2.0$ Hz); ${ }^{13}$ C NMR (100 M Hz DMSO- $\left.d^{6}\right): 150.7,149.1,146.7,146.5,145.4,143.9,142.7$, 133.3, 132.5, 128.6 120.5; HRMS (ESI-TOF) m/z:[M] calcd. for $\mathrm{C}_{10} \mathrm{H}_{7} \mathrm{~N}_{4} \mathrm{O}_{4}$ 247.0462; found 247.0450 .

Synthesis of Compound $\mathbf{3}$.

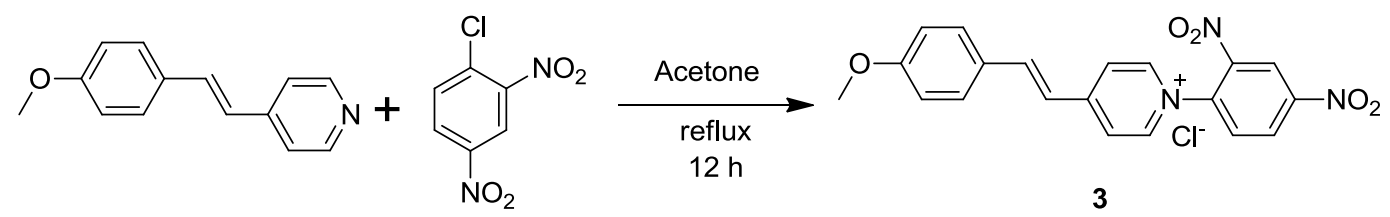


(E)-4-(4-methoxystyryl)pyridine ${ }^{1}(1.05 \mathrm{~g}, 5.0 \mathrm{mmol})$ was dissolved in acetone $(15.0 \mathrm{~mL})$ and stirred, while 2,4- dinitrochlorobenzene $(1.01 \mathrm{~g}, 5.0 \mathrm{mmol})$ was added to the reaction mixture. The mixture was heated under reflux for $12 \mathrm{~h}$ and cooled to room temperature. The precipitate produced was filtered under suction and washed with n-hexane. Yield: $1.90 \mathrm{~g}(72 \%)$; Red solid; ${ }^{1} \mathrm{H}$ NMR (400 M Hz, $\left.\mathrm{CDCl}_{3}\right): 3.86$ (s, 3H), 7.11 (d, 2H, J=8.4 $\mathrm{Hz}), 7.55$ (d, 1H, $J=16.0 \mathrm{~Hz}), 7.89$ (d, 2H, $J=8.0 \mathrm{~Hz}), 8.26$ (d, 1H, $J=16.0 \mathrm{~Hz}), 8.42-$ $8.43(\mathrm{~m}, 3 \mathrm{H}), 8.96(\mathrm{~d}, 1 \mathrm{H}, J=7.6 \mathrm{~Hz}), 9.12-9.18(\mathrm{~m}, 3 \mathrm{H}) ;{ }^{13} \mathrm{C}$ NMR $\left(100 \mathrm{M} \mathrm{Hz}, \mathrm{CDCl}_{3}\right)$ : $162.2,156.5,149.2,145.2,144.2,143.6,139.1,132.4,131.1,130.5,128.1,123.2,121.8$, 121.0, 115.2, 55.9; HRMS (ESI-TOF) m/z:[M] ${ }^{+}$calcd. for $\mathrm{C}_{20} \mathrm{H}_{16} \mathrm{~N}_{3} \mathrm{O}_{5}$ 378.1084; found 379.1080 .

Synthesis of Compound 7.

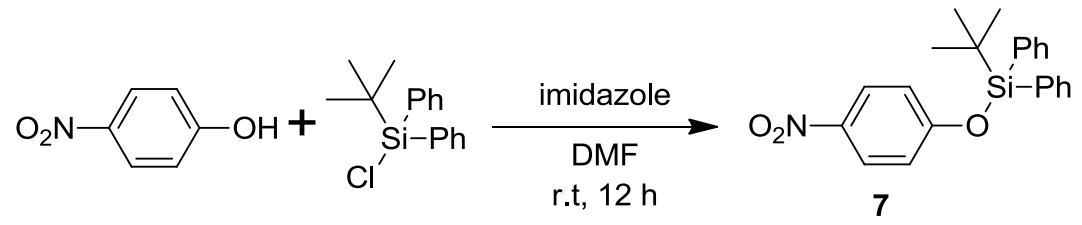

To a stirred solution of 4-nitrophenol $(0.695 \mathrm{~g}, 5 \mathrm{mmol})$ and imidazole $(0.748 \mathrm{~g}, 11.0$ $\mathrm{mmol})$ in DMF (8 $\mathrm{mL})$ at room temperature was added dropwise tert-butyldiphenylsilyl chloride $(1.4 \mathrm{~mL}, 5.5 \mathrm{mmol})$. The reaction mixture was stirred at room temperature for 12 h. Subsequently, water was added and the resulting mixture was extracted with diethyl ether. Combined organic layers were dried over anhydrous $\mathrm{MgSO} 4$ and concentrated under high vacuum. The crude product was purified by column chromatography on silica gel (n-hexane:ethylacetate, 10:1). Yield: $1.70 \mathrm{~g}$ (90\%); White solid; ${ }^{1} \mathrm{H}$ NMR (400 M Hz, $\left.\mathrm{CDCl}_{3}\right): 1.13(\mathrm{~s}, 9 \mathrm{H}), 6.81(\mathrm{~d}, 2 \mathrm{H}, J=6.0 \mathrm{~Hz}), 7.39-7.42(\mathrm{~m}, 4 \mathrm{H}), 7.45-7.50(\mathrm{~m}, 2 \mathrm{H})$, $7.71(\mathrm{dd}, 4 \mathrm{H}, J=8.0 \mathrm{~Hz}, 1.6 \mathrm{~Hz}), 8.01(\mathrm{~d}, 2 \mathrm{H}, J=9.2 \mathrm{~Hz}) ;{ }^{13} \mathrm{C}$ NMR $(100 \mathrm{M} \mathrm{Hz}$, $\left.\mathrm{CDCl}_{3}\right): 161.2,141.7,135.2,135.1,134.7,131.3,130.3,129.5,128.0,127.6,125.5$, 119.8, 26.2, 19.3; HRMS (ESI-TOF) m/z:[M] ${ }^{+}$calcd. for $\mathrm{C}_{22} \mathrm{H}_{23} \mathrm{NO}_{3} \mathrm{Si}$ 377.1447; found 377.1427

Synthesis of Compound 9. 


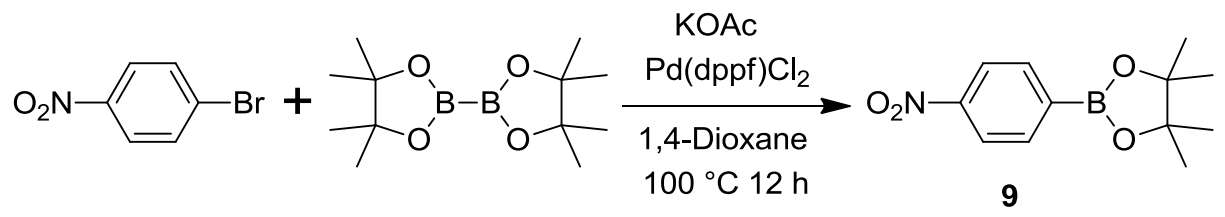

1-bromo-4-nitrobenzene $(0.94 \mathrm{~g}, 4.662 \mathrm{mmol})$, bis(pinacolato)diborane $(1.3 \mathrm{~g}, 5.14$ $\mathrm{mmol}), \mathrm{KOAc}(1.28 \mathrm{~g}, 13.0 \mathrm{mmol}), \mathrm{Pd}(\mathrm{dppf}) \mathrm{Cl}_{2}(0.042 \mathrm{~g}, 0.057 \mathrm{mmol})$ were charged in Schlenk tube inside the glovebox. Dry 1,4-dioxan $(50 \mathrm{~mL})$ was added and the suspension was stirred and heated at $100{ }^{\circ} \mathrm{C}$ under nitrogen atmosphere for $12 \mathrm{~h}$. After cooling the mixture was diluted by adding ethyl acetate. The mixture was filtered and the solvent was extracted successively with water twice and brine once. The organic layer was collected and dried with anhydrous $\mathrm{MgSO}_{4}$. The filtered solution was evaporated. The resulting crude product was purified by silica gel column chromatography ( $n$-hexane:ethylacetate, 50:1). Yield: $0.80 \mathrm{~g}$ (70\%); White solid; ${ }^{1} \mathrm{H}$ NMR (400 M Hz, $\left.\mathrm{CDCl}_{3}\right)$ : 1.36 (s, 12H), 7.95 (d, 2H, $J=8.8 \mathrm{~Hz}), 8.19$ (d, 2H, $J=8.8 \mathrm{~Hz}) ;{ }^{13} \mathrm{C} \mathrm{NMR}\left(100 \mathrm{M} \mathrm{Hz}, \mathrm{CDCl}_{3}\right): 150.0$, 140.0, 135.8, 122.6, 84.8, 25.0; HRMS (ESI-TOF) m/z:[M] ${ }^{+}$calcd. for $\mathrm{C}_{12} \mathrm{H}_{16} \mathrm{BNO}_{4}$ 249.1172; found 249.1170 .

Synthesis of Compound 10.

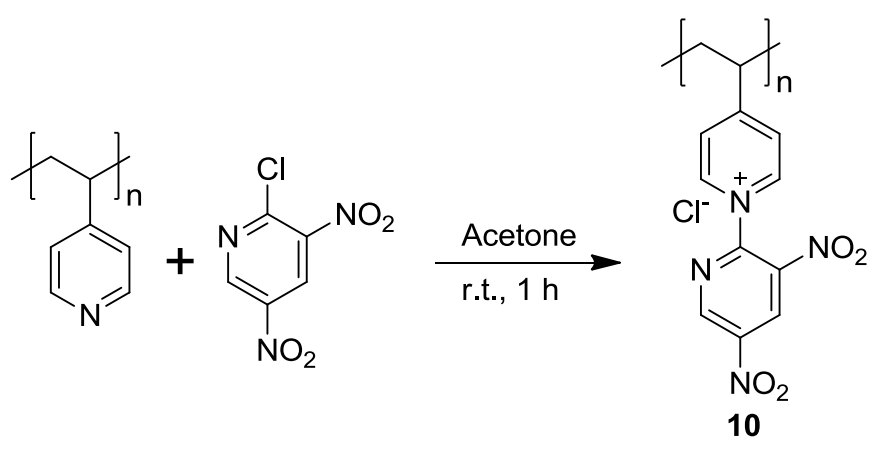

Poly (4-vinylpyridine) $2 \%$ cross-linked with divinylbenzene (100 mg) (Sigma Aldrich) was dispersed in acetone $(10.0 \mathrm{~mL})$ and stirred, while 2-chloro-3,5-dinitropyridine (200 $\mathrm{mg}$ ) was added to the reaction mixture. After 10 minutes the color of dispersed solid changes from white to brown. Stirring was continued for $1 \mathrm{~h}$. Then the solid was filtered under suction and washed with dichloromethane followed by $n$-hexane. Dinitropyridyl loading $(0.98 \mathrm{mmol} / \mathrm{g})$ was determined by stripping 10 with an excess of thiophenol and measuring the concentration of 2 . 


\section{NMR Spectra}

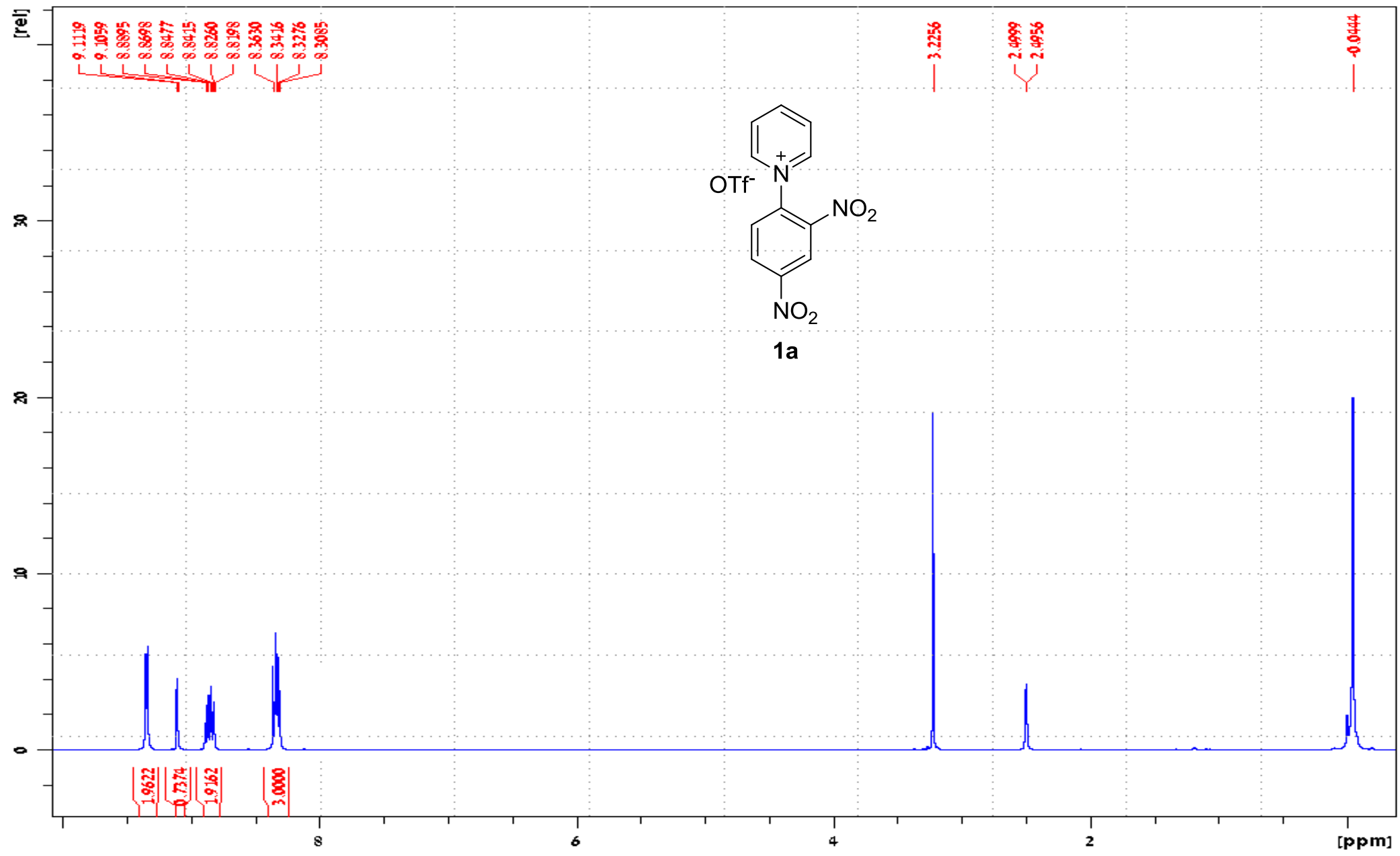

Figure S1. ${ }^{1} \mathrm{H}$ NMR spectrum of $\mathbf{1 a}$ in DMSO- $d^{6}$. 


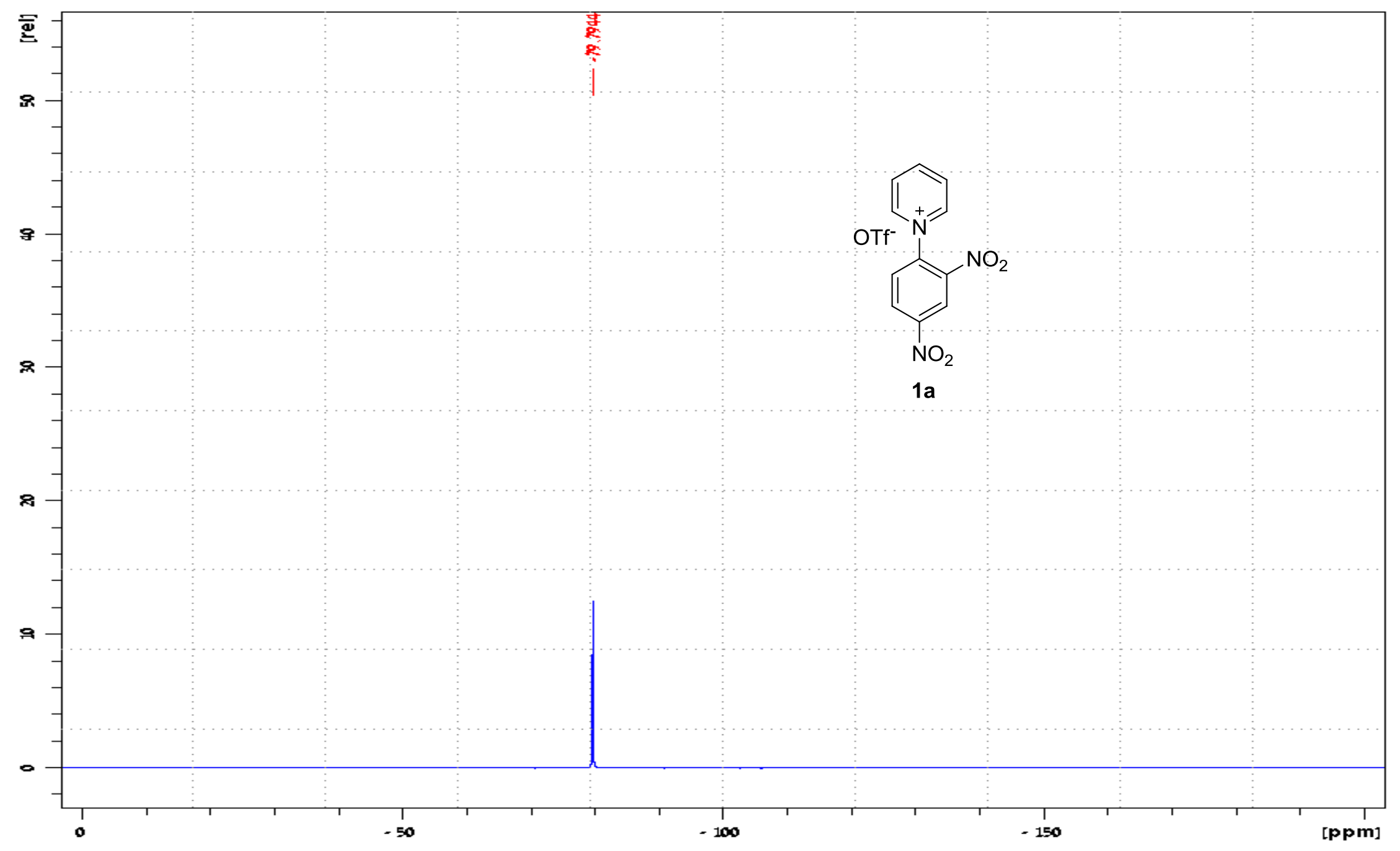

Figure S2. ${ }^{19} \mathrm{~F}$ NMR spectrum of 1a in DMSO- $d^{6}$. 


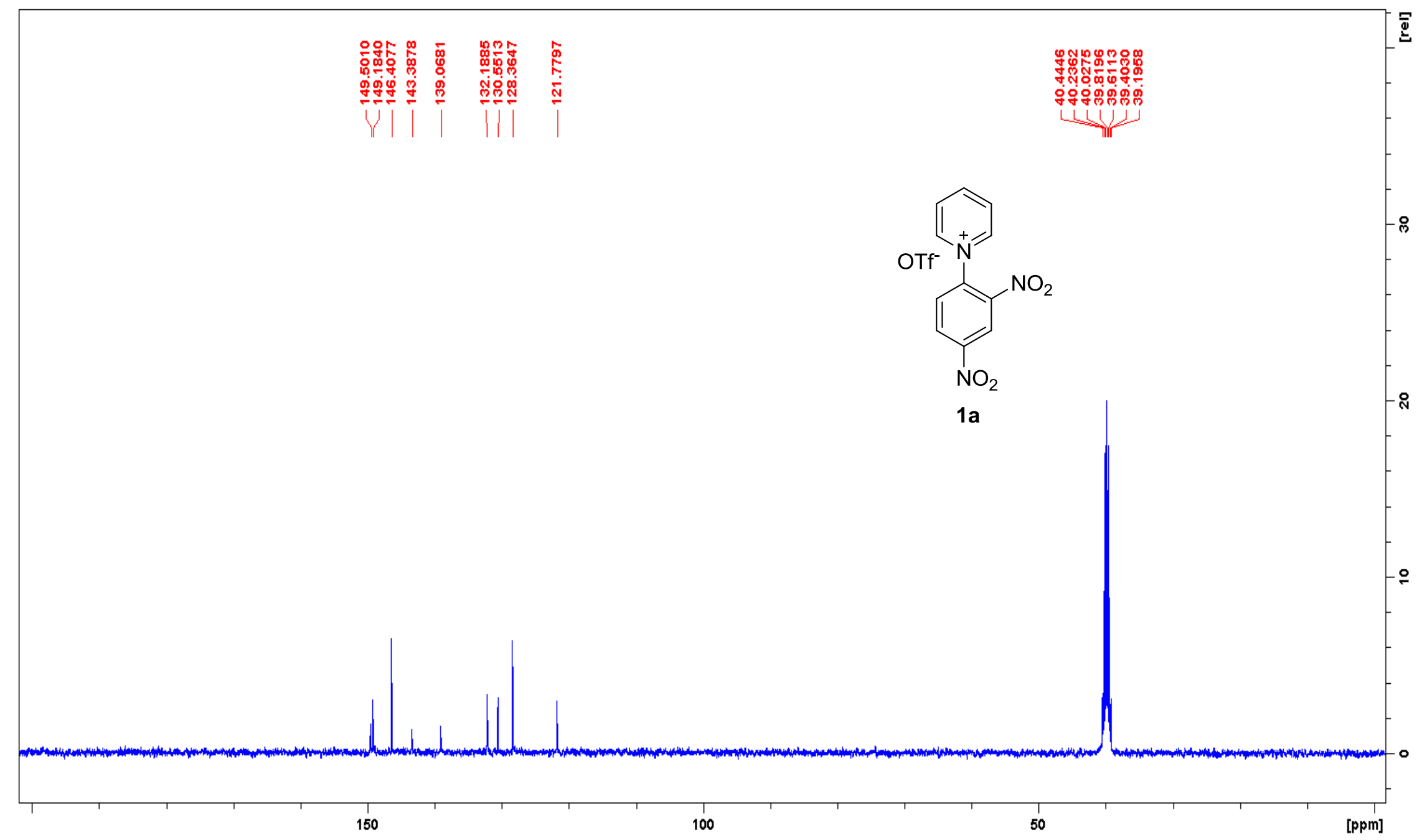

Figure S3. ${ }^{13} \mathrm{C}\left\{{ }^{1} \mathrm{H}\right\}$ NMR spectrum of 1a in DMSO- $d^{6}$. 


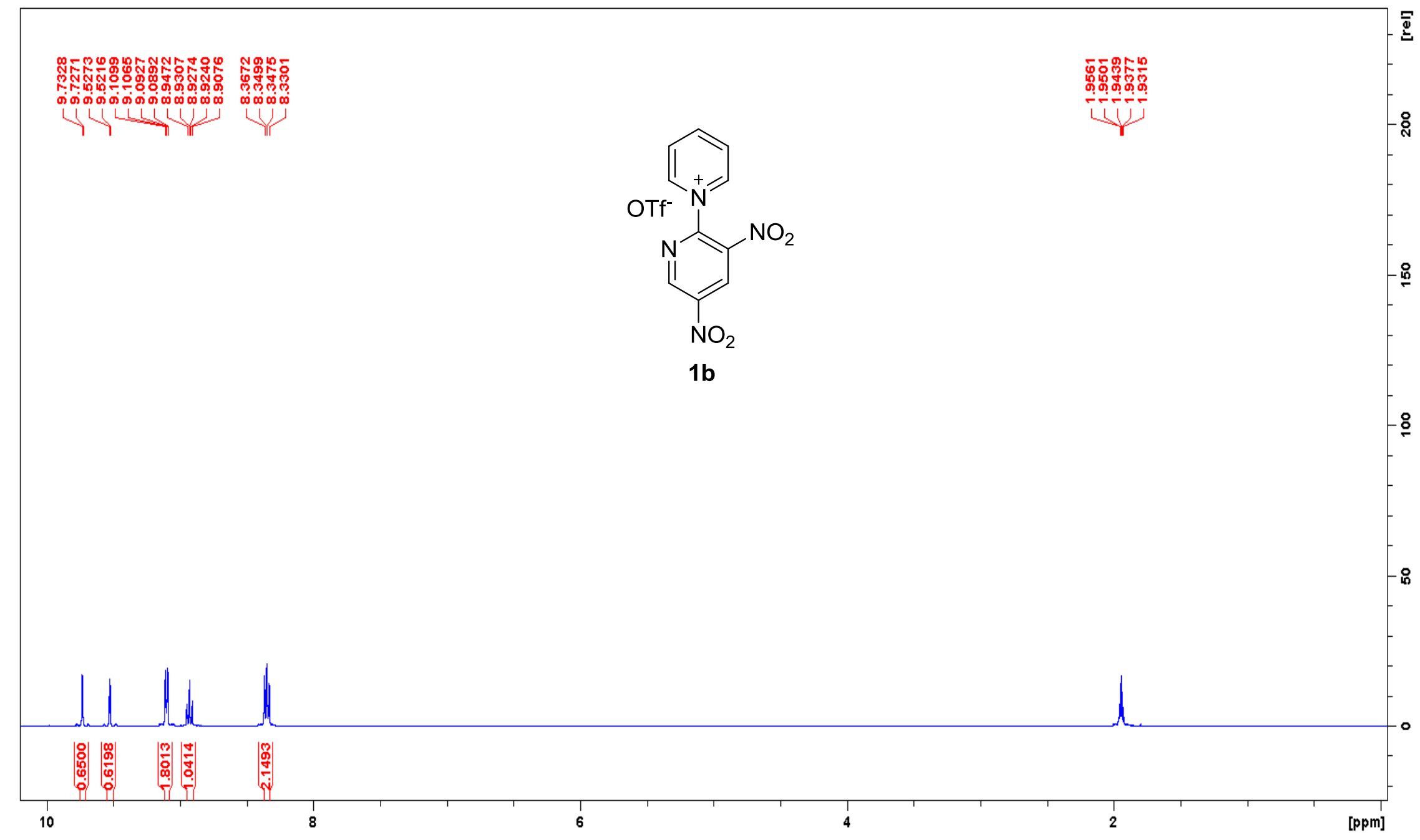

Figure S4. ${ }^{1} \mathrm{H}$ NMR spectrum of $\mathbf{1 b}$ in $\mathrm{CD}_{3} \mathrm{CN}$. 


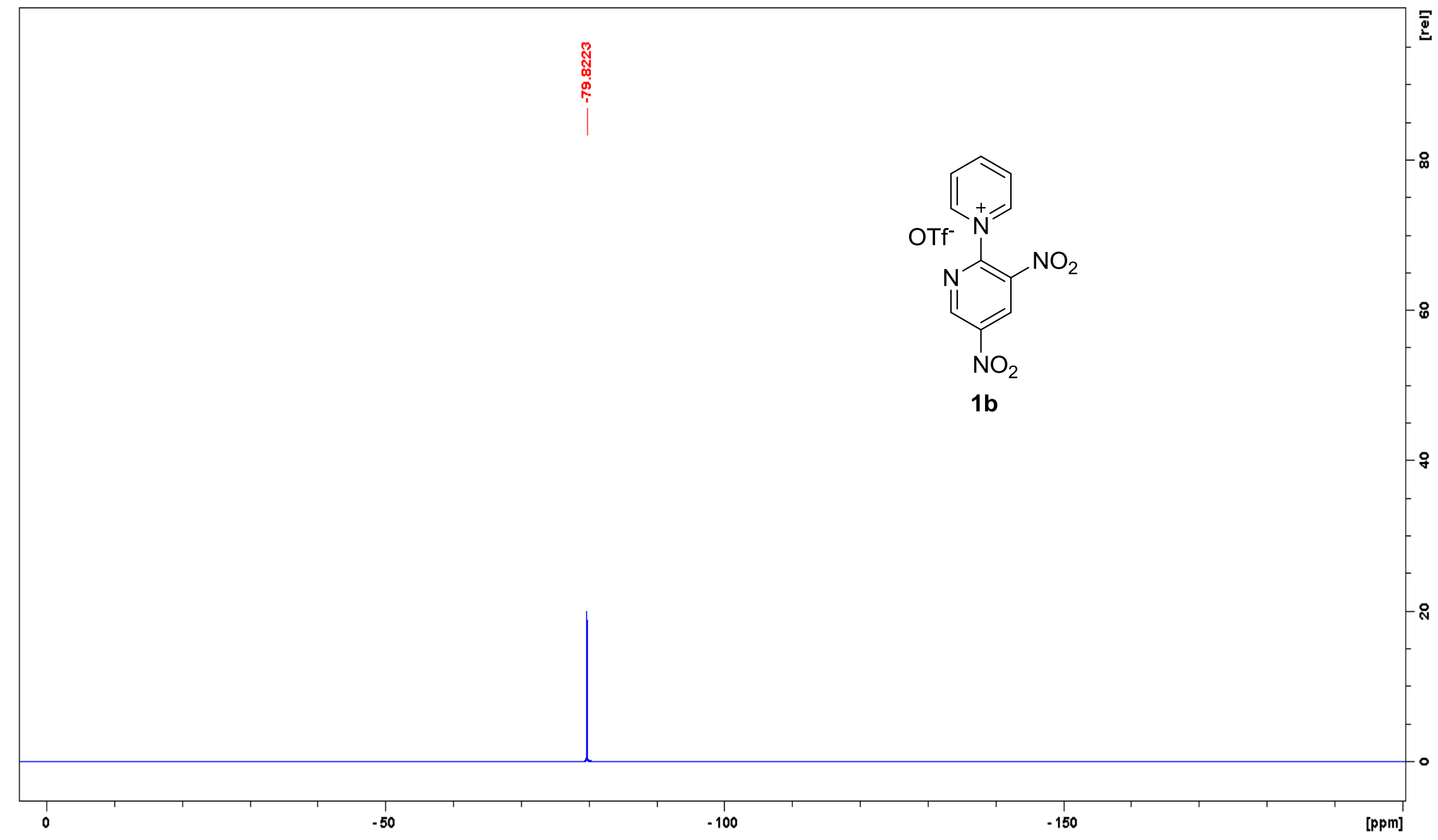

Figure S5. ${ }^{19} \mathrm{~F}$ NMR spectrum of $\mathbf{1 b}$ in $\mathrm{CD}_{3} \mathrm{CN}$. 


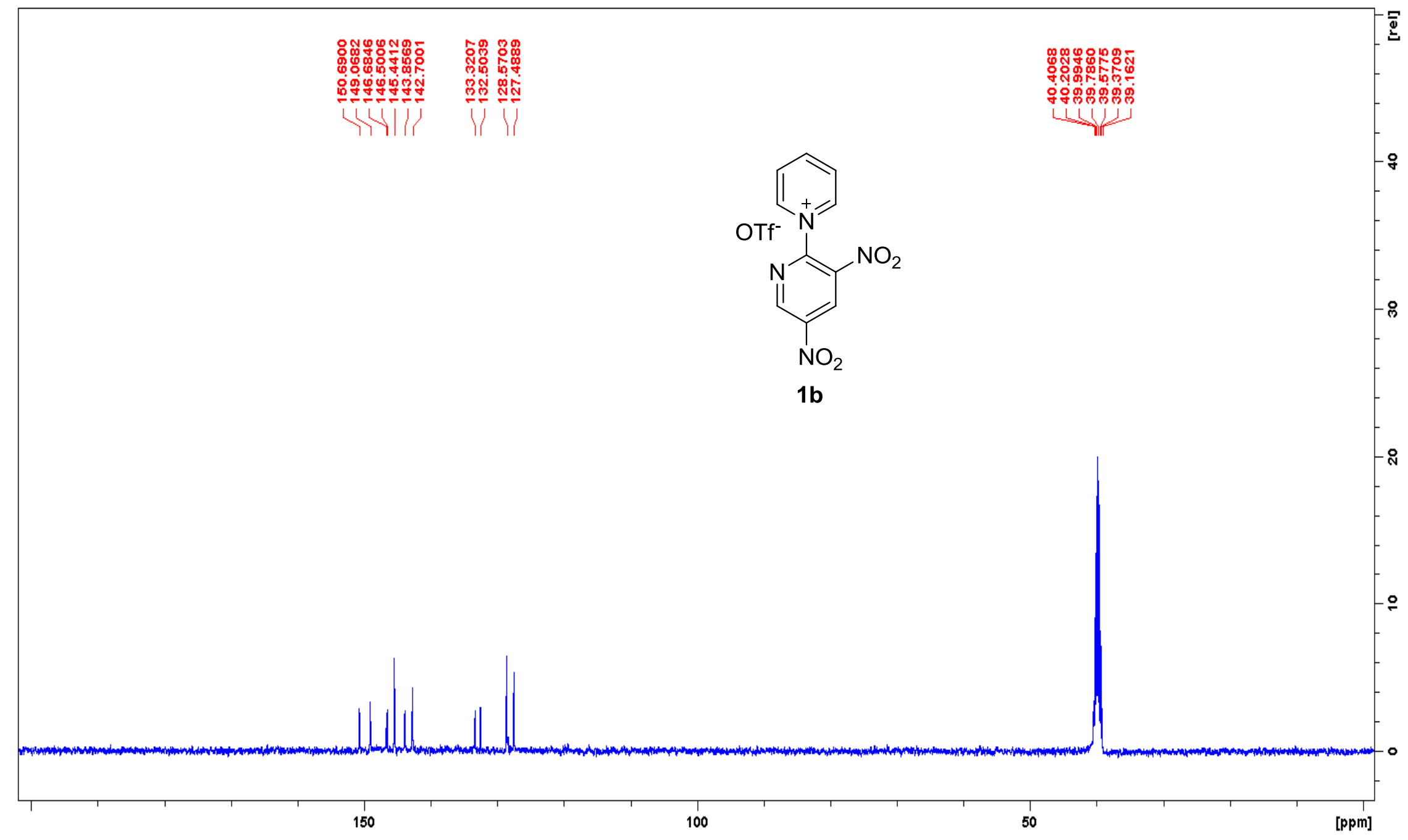

Figure S6. ${ }^{13} \mathrm{C}\left\{{ }^{1} \mathrm{H}\right\}$ NMR spectra of $\mathbf{1 b}$ in DMSO- $d^{6}$. 


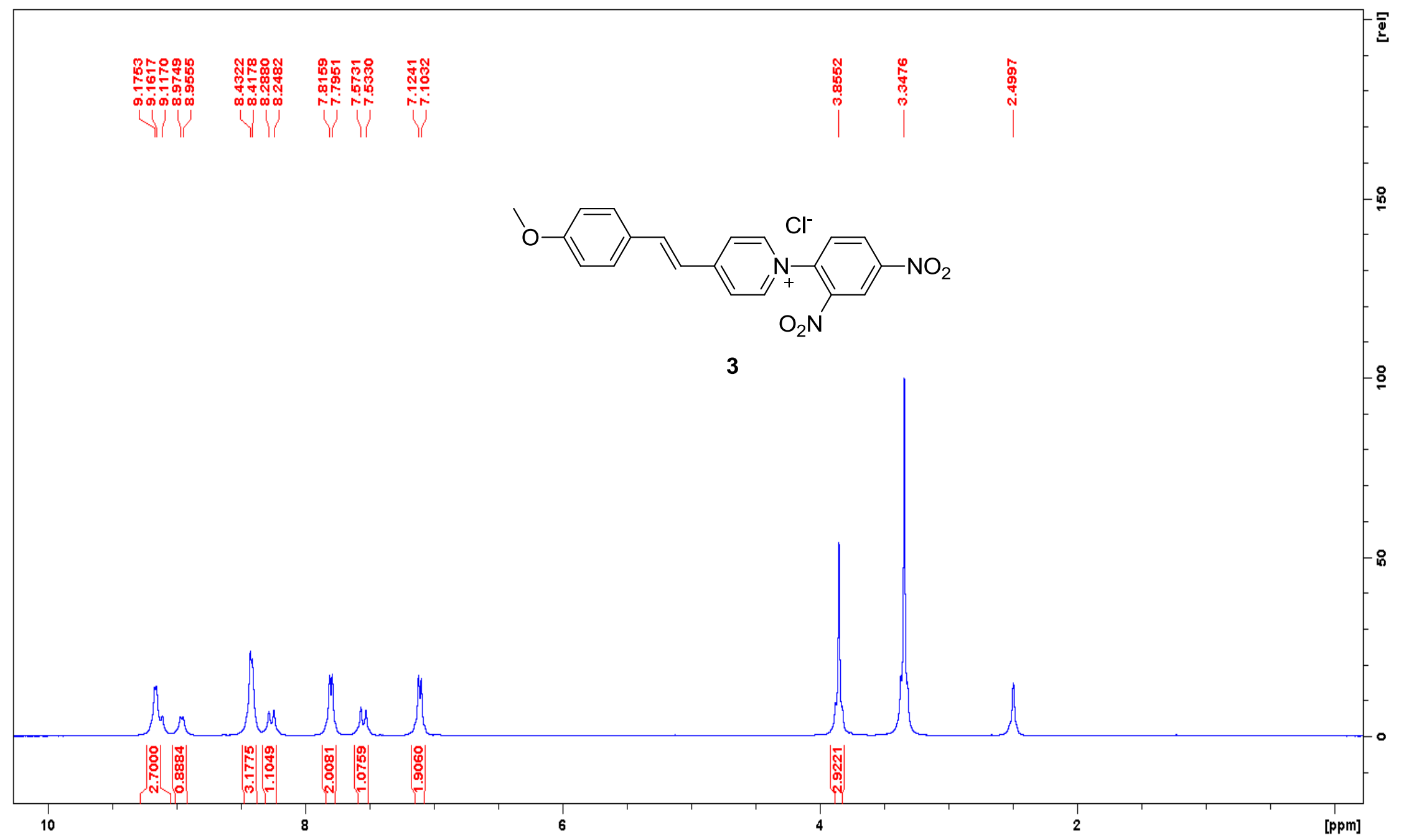

Figure S7. ${ }^{1} \mathrm{H}$ NMR spectrum of 3 in DMSO- $d^{6}$. 


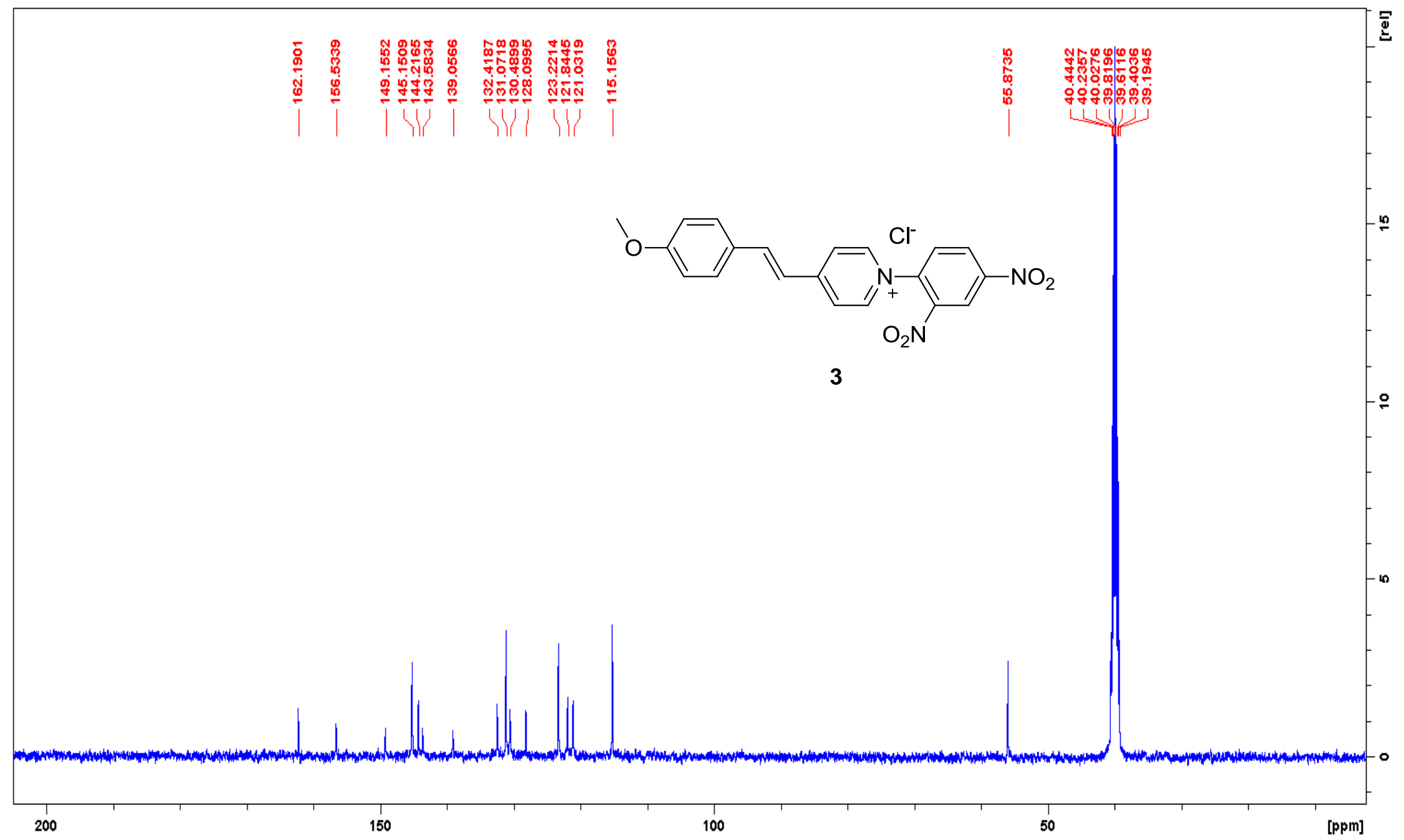

Figure S8. ${ }^{13} \mathrm{C}\left\{{ }^{1} \mathrm{H}\right\}$ NMR spectrum of 3 in DMSO- $d^{6}$. 


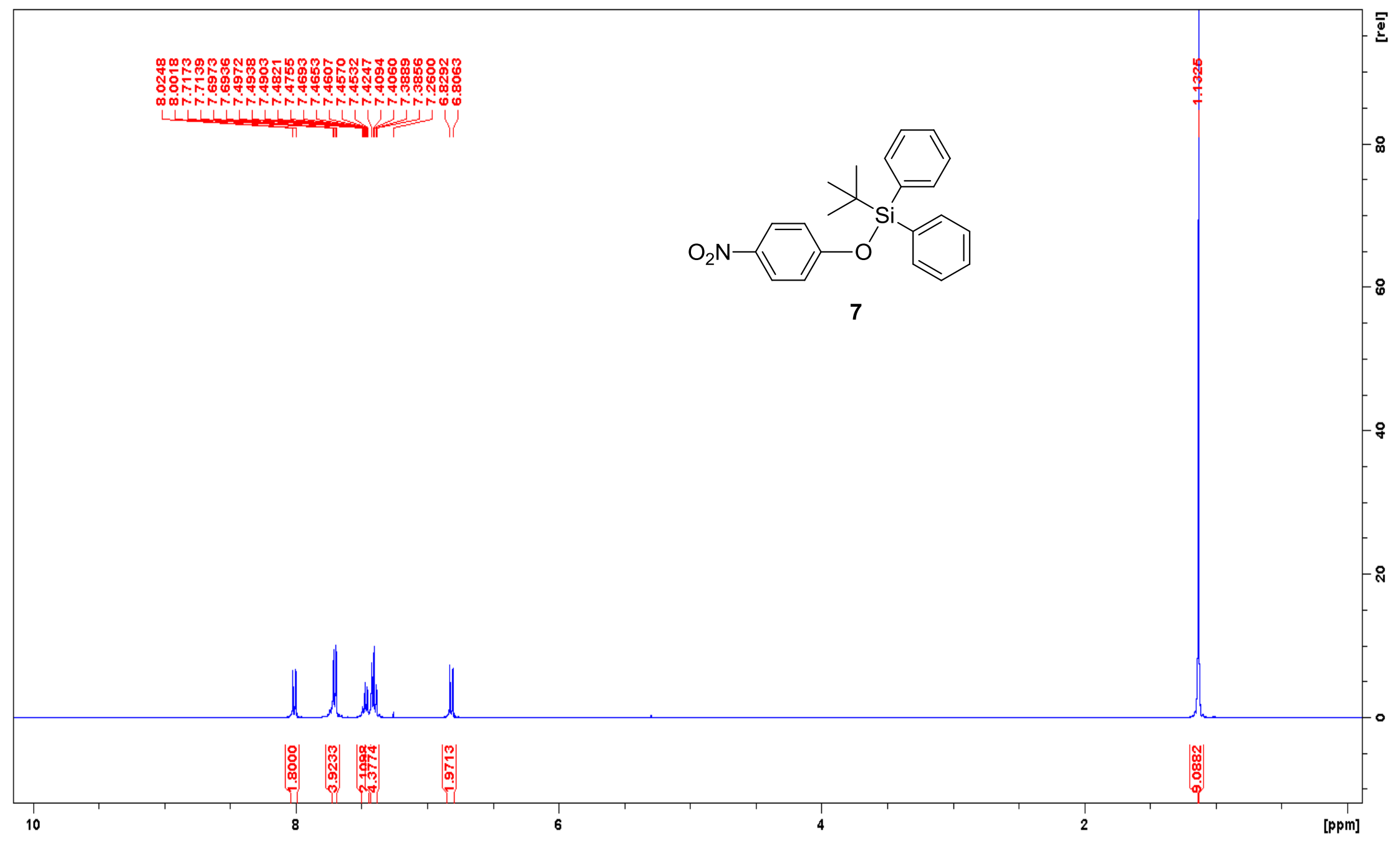

Figure S9. ${ }^{1} \mathrm{H}$ NMR spectrum of 7 in $\mathrm{CDCl}_{3}$. 


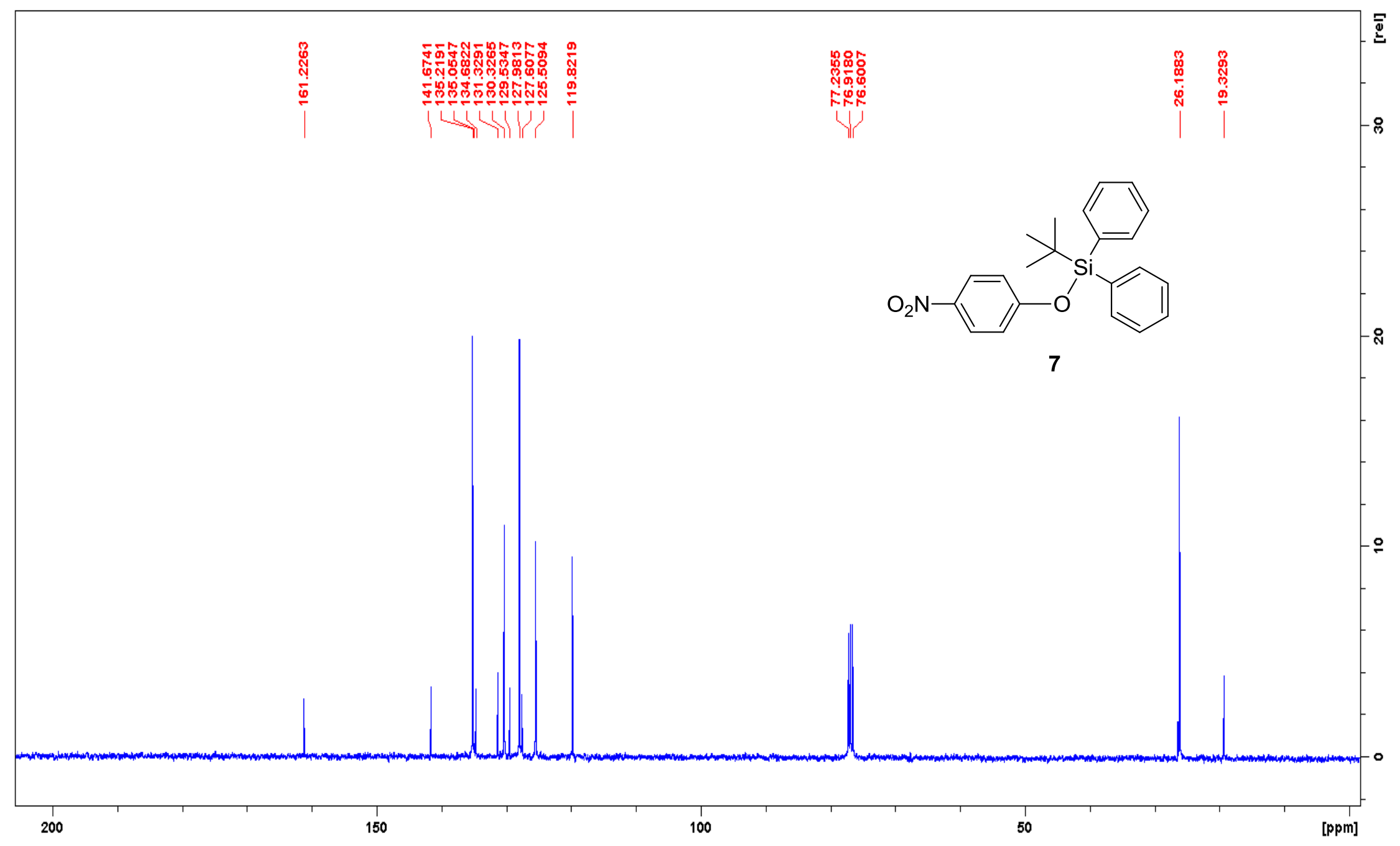

Figure S10. ${ }^{13} \mathrm{C}\left\{{ }^{1} \mathrm{H}\right\}$ NMR spectrum of 7 in $\mathrm{CDCl}_{3}$. 


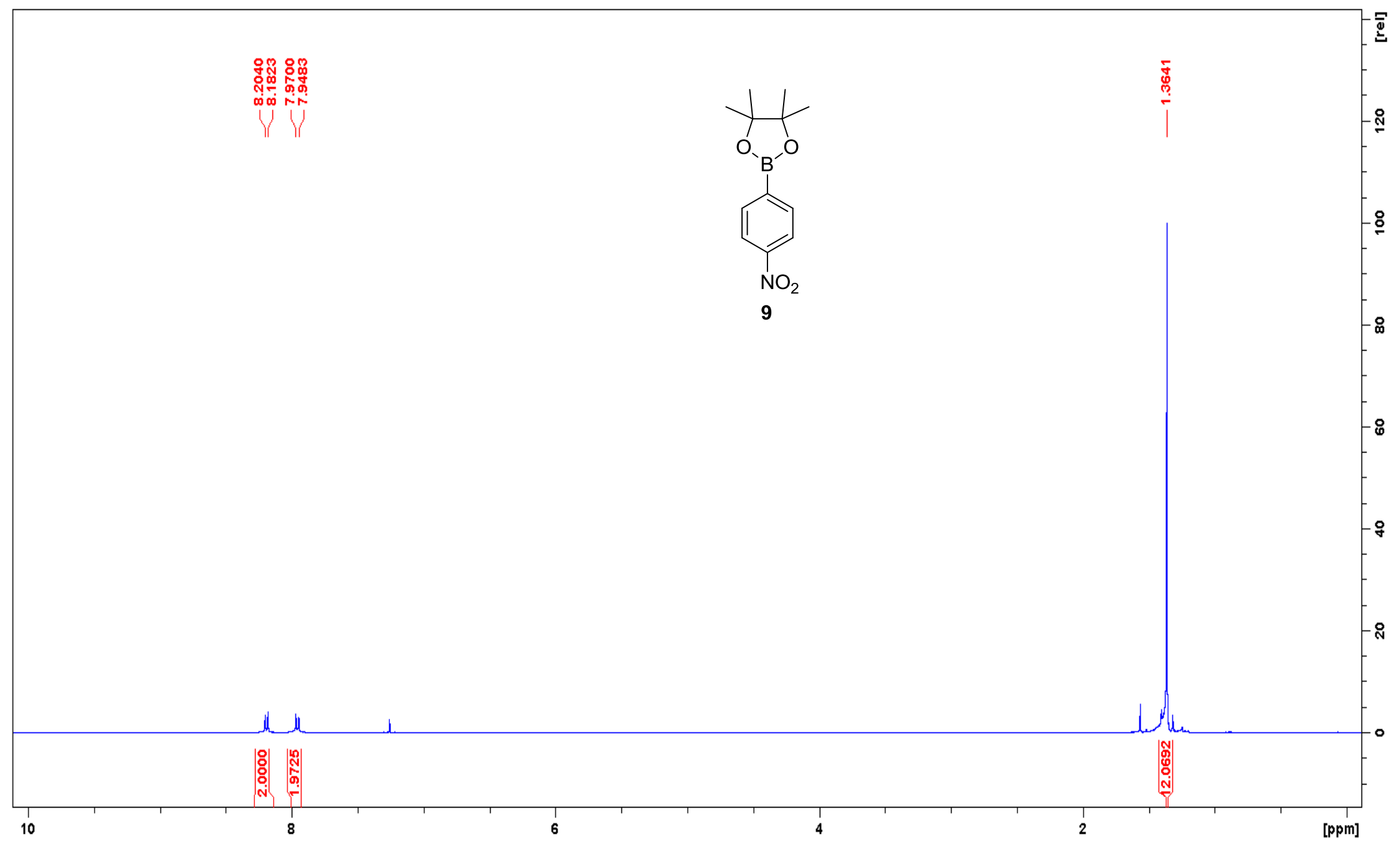

Figure S11. ${ }^{1} \mathrm{H}$ NMR spectrum of 9 in $\mathrm{CDCl}_{3}$. 


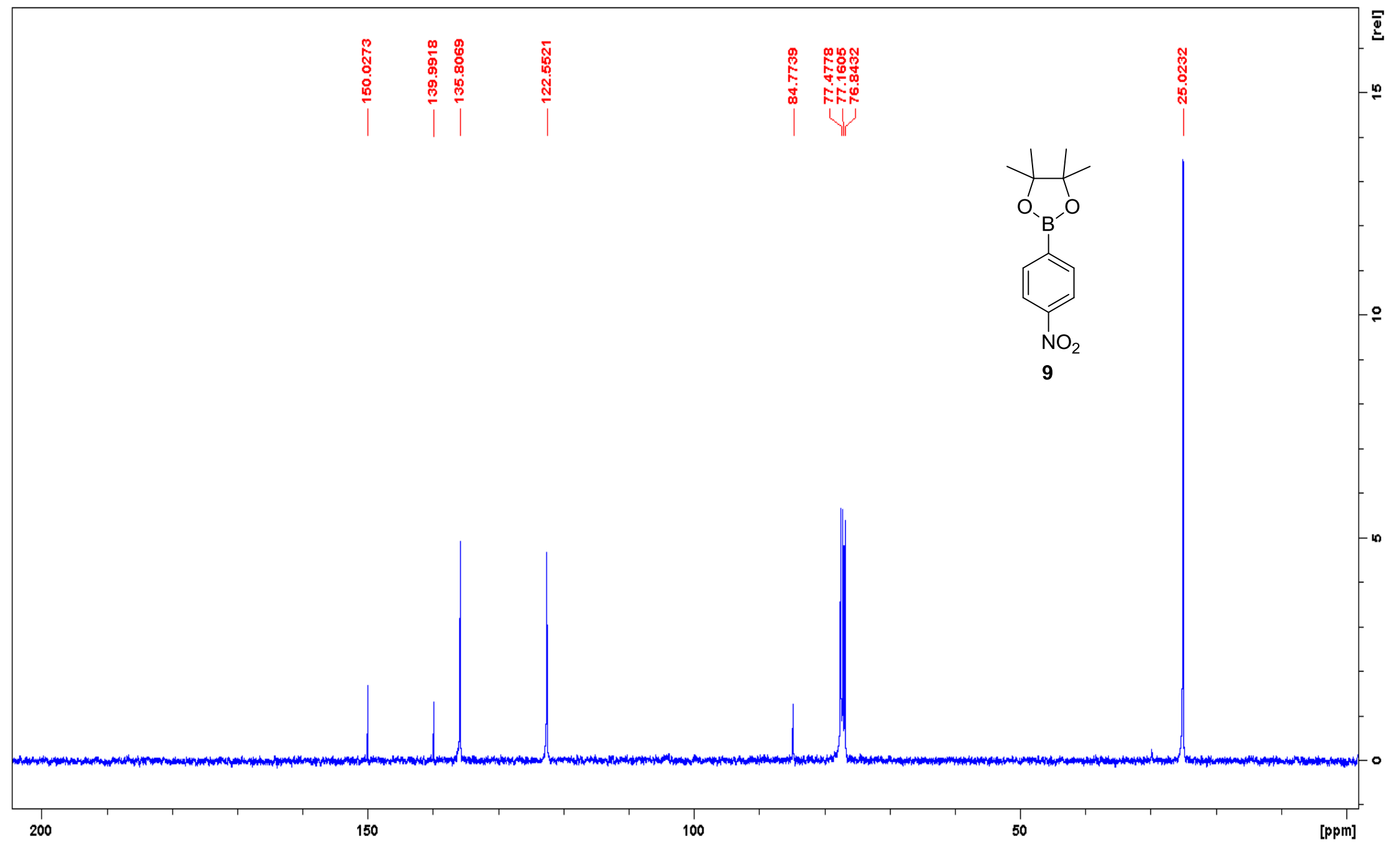

Figure S12. ${ }^{13} \mathrm{C}\left\{{ }^{1} \mathrm{H}\right\}$ NMR spectrum of 9 in $\mathrm{CDCl}_{3}$. 


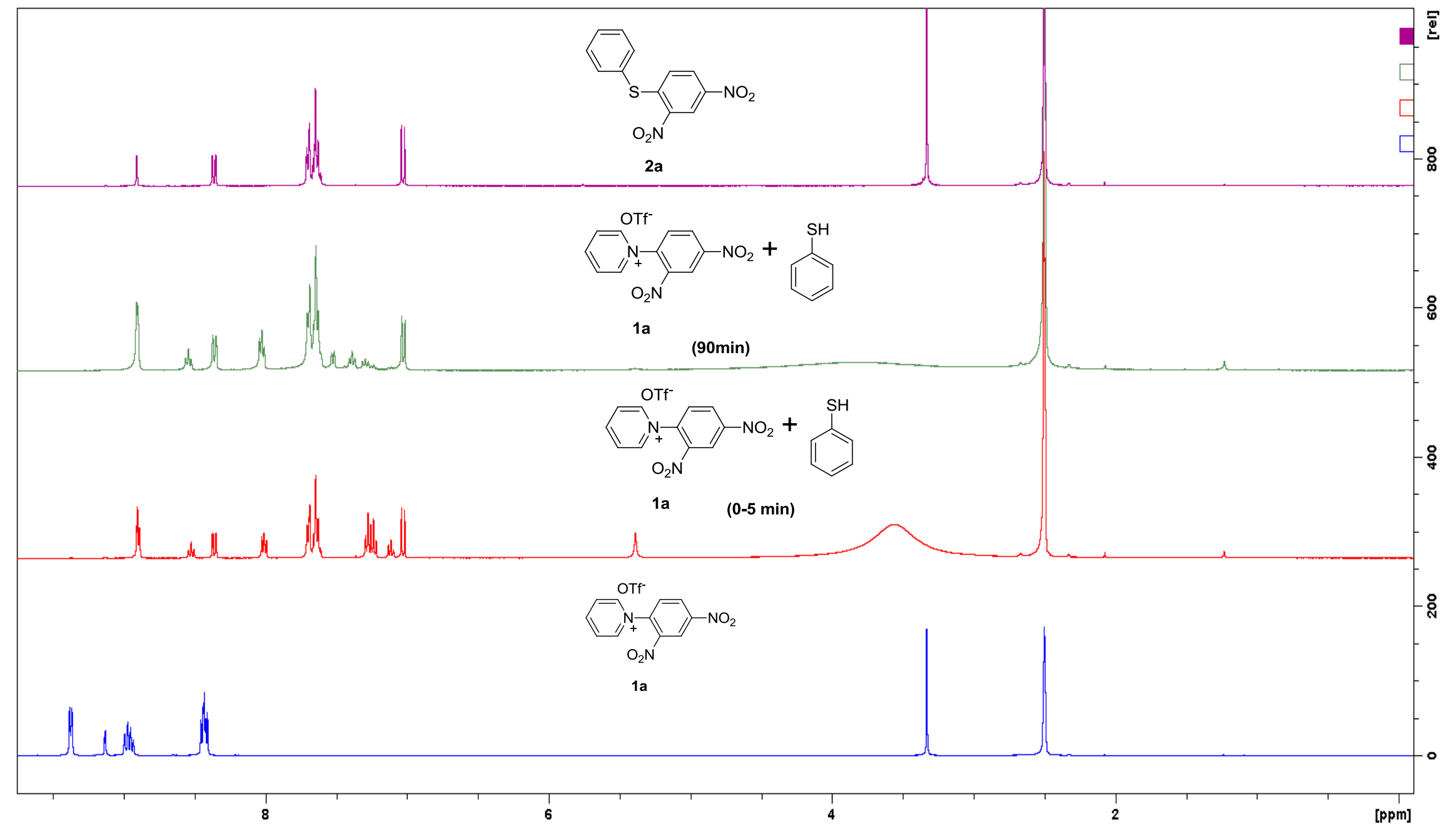

Figure S13. ${ }^{1} \mathrm{H}$ NMR spectra of $\mathbf{1 a}$ with thiophenol and the product in DMSO- $d^{6}$. 


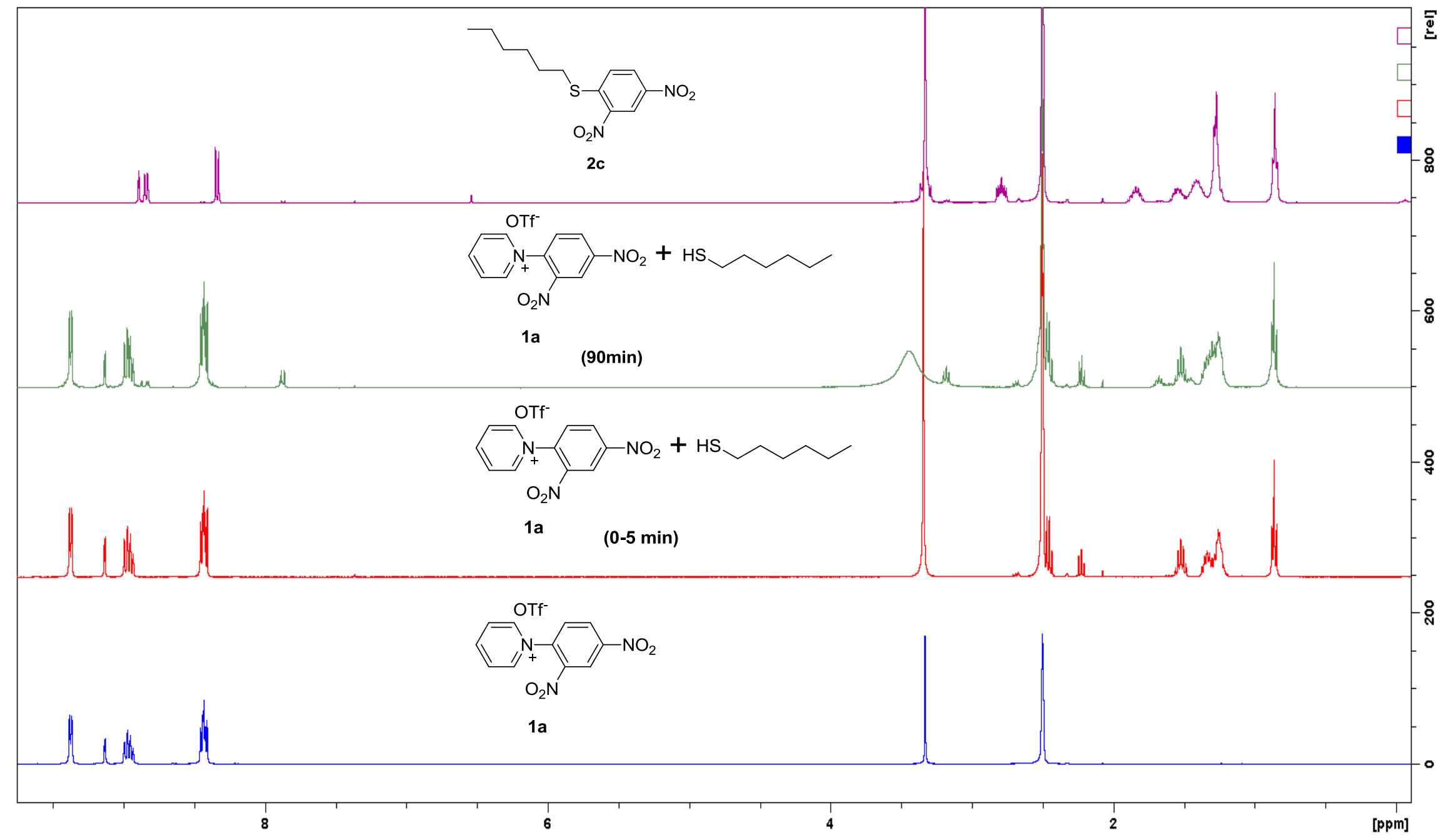

Figure S14. ${ }^{1} \mathrm{H}$ NMR spectra of 1a with hexylthiol and the product in DMSO- $d{ }^{6}$. 


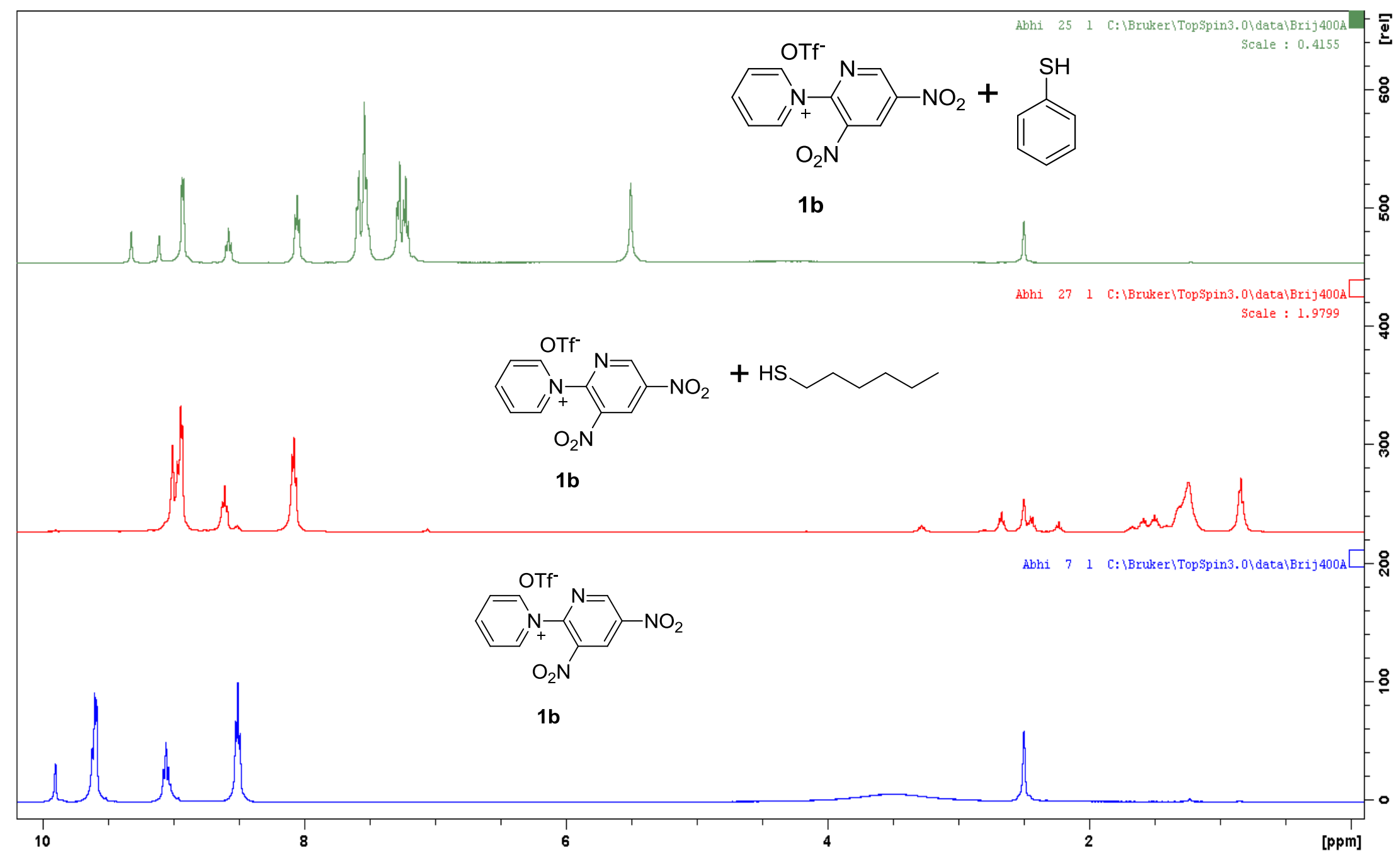

Figure S15. ${ }^{1} \mathrm{H}$ NMR spectra of $\mathbf{1 b}$ with hexylthiol and thiophenol in DMSO- $d^{6}$. 


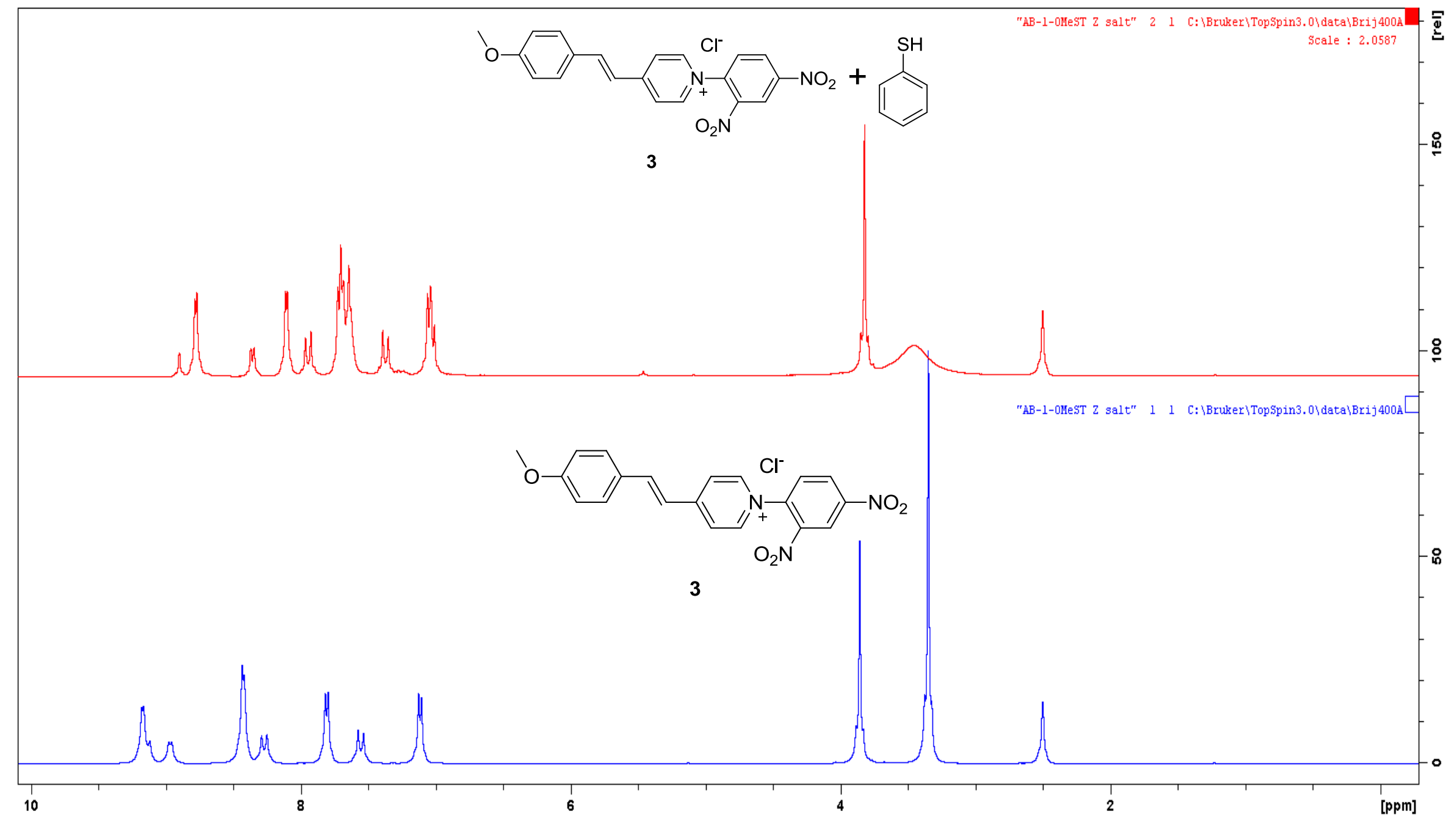

Figure S16. ${ }^{1} \mathrm{H}$ NMR spectra of 3a with thiophenol in DMSO- $d^{6}$. 


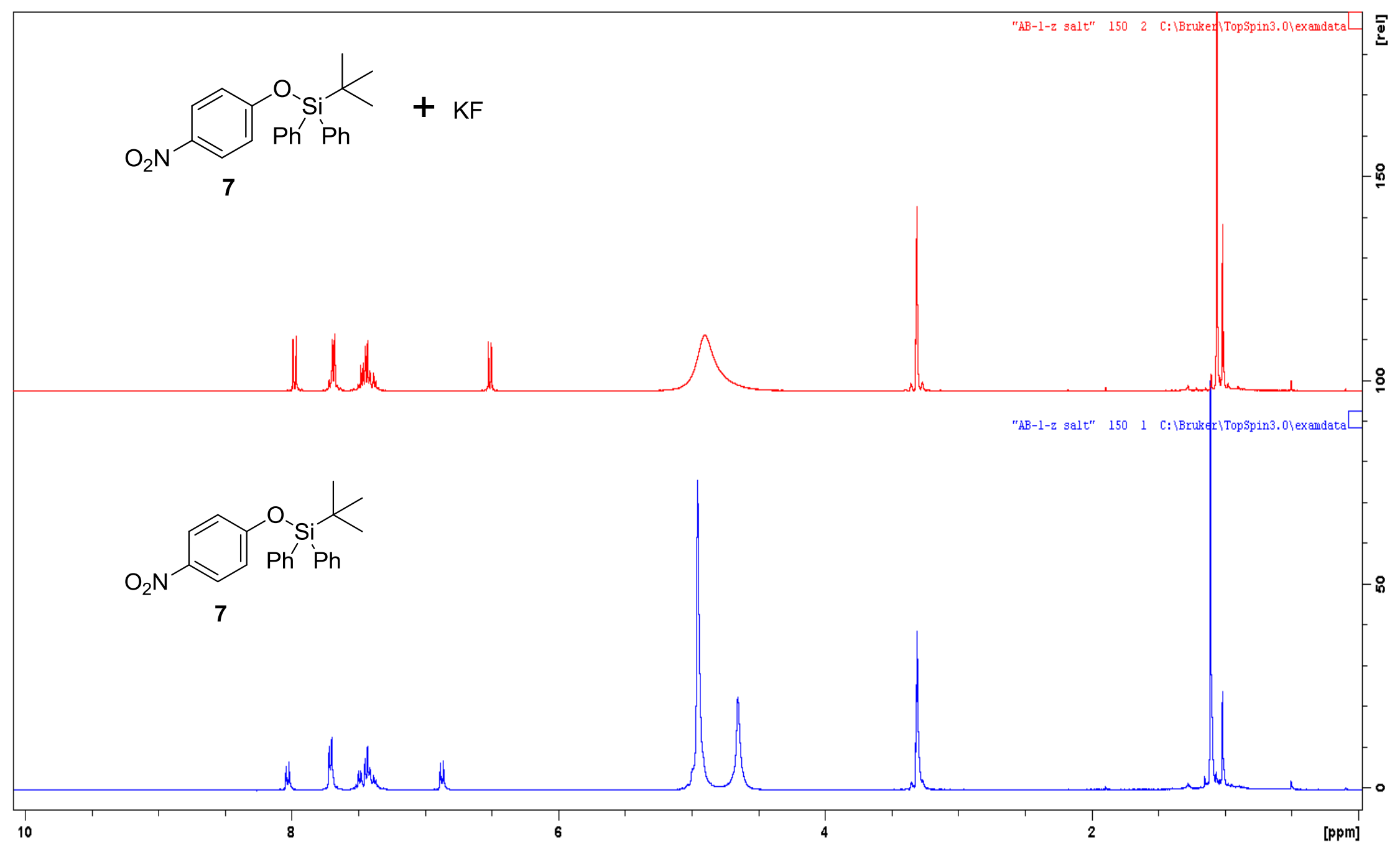

Figure S17. ${ }^{1} \mathrm{H}$ NMR spectra of 7 with $\mathrm{KF}$ in $\mathrm{CD}_{3} \mathrm{OD}: \mathrm{D}_{2} \mathrm{O}(9: 1)$. 


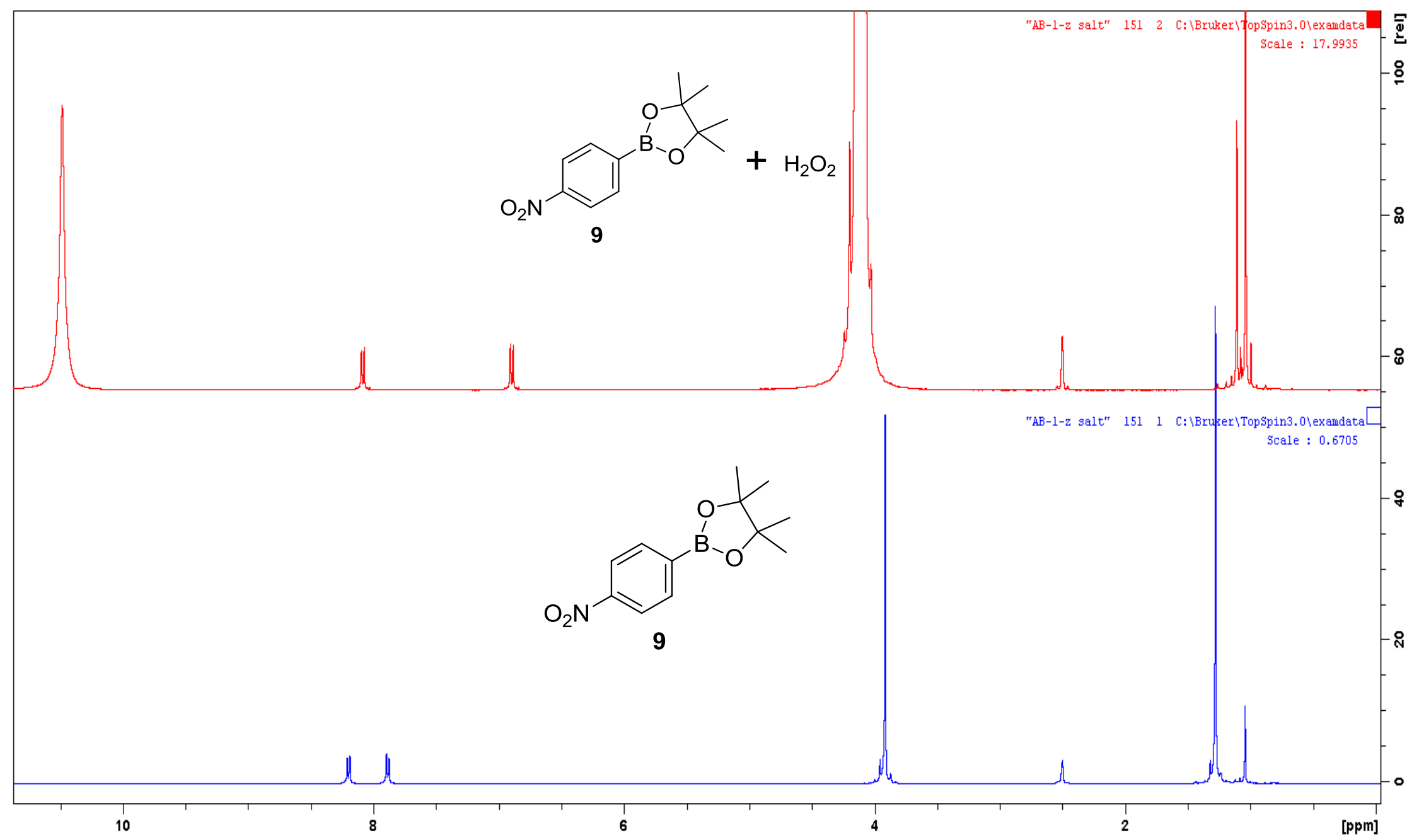

Figure S18. ${ }^{1} \mathrm{H}$ NMR spectra of 9 with $\mathrm{H}_{2} \mathrm{O}_{2}$ in DMSO- $d^{6}$ : $\mathrm{D}_{2} \mathrm{O}(9: 1)$. 

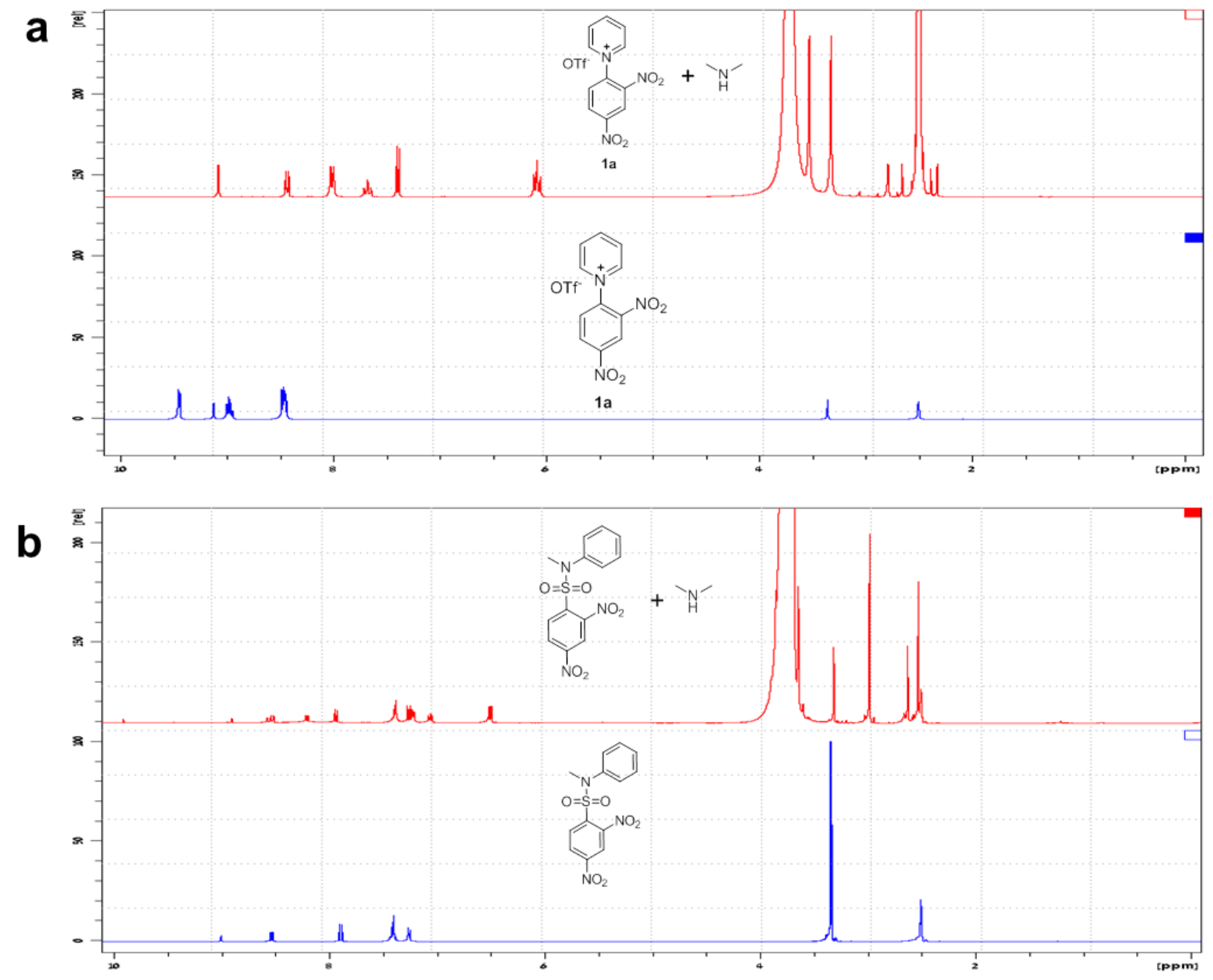

Figure S19. a) ${ }^{1} \mathrm{H}$ NMR spectra showing the reaction of 1a with dimethylamine in DMSO- $d^{6}$. b) Reactivity of dinitrosulphonamide, a common reactive group used for thiol detection, ${ }^{2}$ with dimethylamine $\left({ }^{1} \mathrm{H}\right.$ NMR spectra in DMSO- $\left.d^{6}\right)$. 


\section{Analyte detection experiments}

Thiol detection with 1 (Turn Off response)

A stock solution of fluorophore I $(1 \mathrm{mM})$ in DMSO was diluted to appropriate concentrations (i.e., $20 \mu \mathrm{M}$ for absorption spectra). To this, the solution of $\mathbf{1 a} / \mathbf{1} \mathbf{b}$ (stock concentration of $10 \mathrm{mM}$ in DMSO) was added to reach the final concentration of $80 \mu \mathrm{M}$. Then, various thiols $(80 \mu \mathrm{M})$ were separately added to this mixture and absorption spectra were recorded. For the emission measurements, $2 \mu \mathrm{M}$ of $\mathbf{I}$ in DMSO was mixed with $\mathbf{1 a} / \mathbf{1 b}(8 \mu \mathrm{M})$ followed by addition of a thiol $(8 \mu \mathrm{M})$.

For the kinetic measurements, $2 \mu \mathrm{M}$ of I in DMSO was mixed with $1 \mathbf{a}$ ( $4 \mu \mathrm{M}$ and $24 \mu \mathrm{M}$, respectively). Hexylthiol $(8 \mu \mathrm{M})$ was separately added to these mixtures and emission spectra were recorded (slit: $2.5 / 5)$ at different time interval.

Thiol detection with $\mathbf{3}$ (Turn On response)

To a solution of fluorophore II $(10 \mu \mathrm{M})$ in DMSO, stock solution of $\mathbf{3}$ was added $(10 \mathrm{mM}$ in DMSO) to reach the final concentration of $40 \mu \mathrm{M}$. Then, various thiols $(40 \mu \mathrm{M})$ were added to this mixture and absorption spectra were recorded. For the emission measurements, $1 \mu \mathrm{M}$ of $\mathbf{I}$ in DMSO was mixed with $3(4 \mu \mathrm{M})$ followed by addition of a thiol $(4 \mu \mathrm{M})$.

Thiol detection with 5 (Ellman's reagent)

To a solution of fluorophore $\mathbf{I}(20 \mu \mathrm{M})$ in ethanol:water $(1: 1)$, stock solution of 5 (2 mM in deionized water) to reach the final concentration of $80 \mu \mathrm{M}$. Then, various thiols (40 $\mu \mathrm{M})$ were added to this mixture and absorption spectra were recorded. For the emission measurements, $0.1 \mu \mathrm{M}$ of $\mathbf{I}$ in ethanol:water $(1: 1)$ was mixed with $5(5 \mu \mathrm{M})$, followed by addition of a thiol $(5 \mu \mathrm{M})$.

\section{Detection of the Fluoride ion with 7}

A stock solution of fluorophore $\mathbf{I}$ in methanol : water (9:1) was diluted to appropriate concentrations (i.e,. $10 \mu \mathrm{M}$ for absorption spectra). To this, the solution of 7 (stock concentration of $10 \mathrm{mM}$ methanol : water (9:1)) was added to reach the final concentration of $500 \mu \mathrm{M}$. Then, KF solution in deionized water (stock concentration 10 
$\mathrm{mM}$ ) was added to reach the final concentration of $100 \mu \mathrm{M}$ and their UV absorption spectra were measured after 50 minutes. For the emission measurements, $10 \mu \mathrm{M}$ of $\mathbf{I}$ in methanol : water $(9: 1)$ was mixed with $7(500 \mu \mathrm{M})$, followed by addition of KF solution in deionized water $(10 \mu \mathrm{M})$ and emission spectra were recorded after different time intervals.

Fluoride selectivity studies

Stock solutions $(10 \mathrm{mM})$ of potentially competing salts: $\mathrm{KOAc}, \mathrm{KCl}, \mathrm{KBr}, \mathrm{KI}, \mathrm{NaHCO}_{3}$ and $\mathrm{KOH}$ in deionized water were prepared. To a solution of $\mathbf{I}(10 \mu \mathrm{M})$ and $7(500 \mu \mathrm{M})$ in methanol : water $(9: 1)$ an equal volume of a solution of a potentially competing analyte $(100 \mu \mathrm{M}$ each) was added. The fluorescence responses were recorded after 50 minutes (slit: $2.5 / 5$ ) and compared with KF.

Detection of hydrogen peroxide with 9

A stock solution of fluorophore $\mathbf{I}$ in ethanol:water (9:1) was diluted to appropriate concentrations (i.e, $10 \mu \mathrm{M}$ ) for absorption spectra. To this, a solution of 9 (stock concentration of $10 \mathrm{mM})$ in ethanol : water $(9: 1)$ was mixed to reach the final concentration of $50 \mu \mathrm{M}$. Then, $\mathrm{H}_{2} \mathrm{O}_{2}$ (Stock solution of $10 \mathrm{mM}$ in carbonate buffer, $\mathrm{pH}$ 9.2) was added to reach the final concentration of $10 \mu \mathrm{M}$ and their absorption and emission spectra were recorded (slit: 2.5/5) after 30 minutes.

$\mathrm{H}_{2} \mathrm{O}_{2}$ selectivity studies

Stock solutions $(10 \mathrm{mM})$ of oxidants $\mathrm{NaOCl}, t$-BuOOH and meta-chloroperbenzoic acid (m-CPBA) in deionized water were prepared. To a solution of $\mathbf{I}(10 \mu \mathrm{M})$ and $\mathbf{9}(50 \mu \mathrm{M})$ in methanol : water $(9: 1)$ an equal volume of a solution of potential competing analyte (10 $\mu \mathrm{M}$ each) was added. The fluorescence responses were recorded 30 minutes after addition of the analytes (slit: 2.5/5) and compared with $\mathrm{H}_{2} \mathrm{O}_{2}$.

Determination of unknown thiol concentration using calibration curve

Ten different solutions of mixture of $\mathbf{I}(2 \mu \mathrm{M})$ and $\mathbf{1 b}(10 \mu \mathrm{M})$ were prepared by varying amount of 2-mercapto ethanol (0-5 eq.). After preparing the calibration solutions, the emission spectra of each solution were recorded. These data were used to prepare a calibration curve $\left(\lambda_{\text {ex. }}=365 \mathrm{~nm}\right)$. Further a solution of 2-mercapto ethanol $(16 \mu \mathrm{M})$ (used 
as unknown) in $5 \mathrm{~mL}$ DMSO was passed through a plug of $\mathbf{1 0}$ and collected in downstream cuvette having I $(4 \mu \mathrm{M})$ in $5 \mathrm{~mL}$ DMSO. The emission intensity of this mixture having the final concentration of $\mathbf{I}(2 \mu \mathrm{M})$, was used in the calibration curve and the concentration of unknown thiol was calculated. 


\section{Absorption and emission spectra}

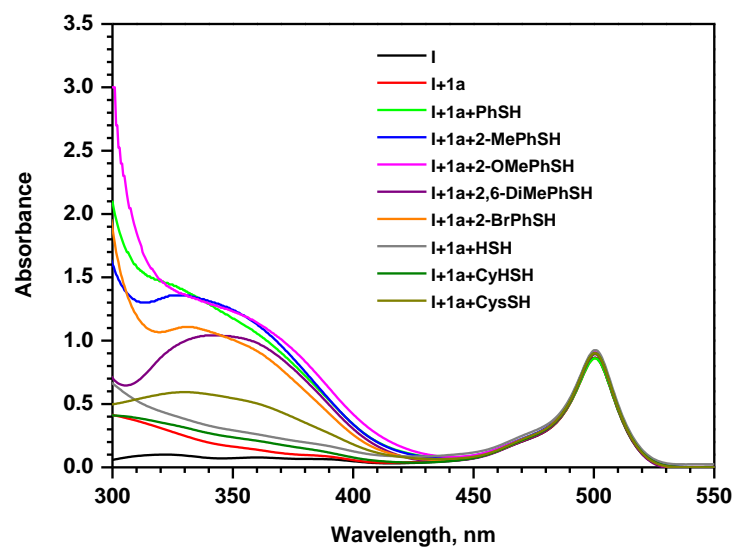

Figure S20. Absorption spectra of I $(20 \mu \mathrm{M})$ with $1 \mathbf{a}(80 \mu \mathrm{M})$ and different thiols (80 $\mu \mathrm{M})$ recorded in DMSO.
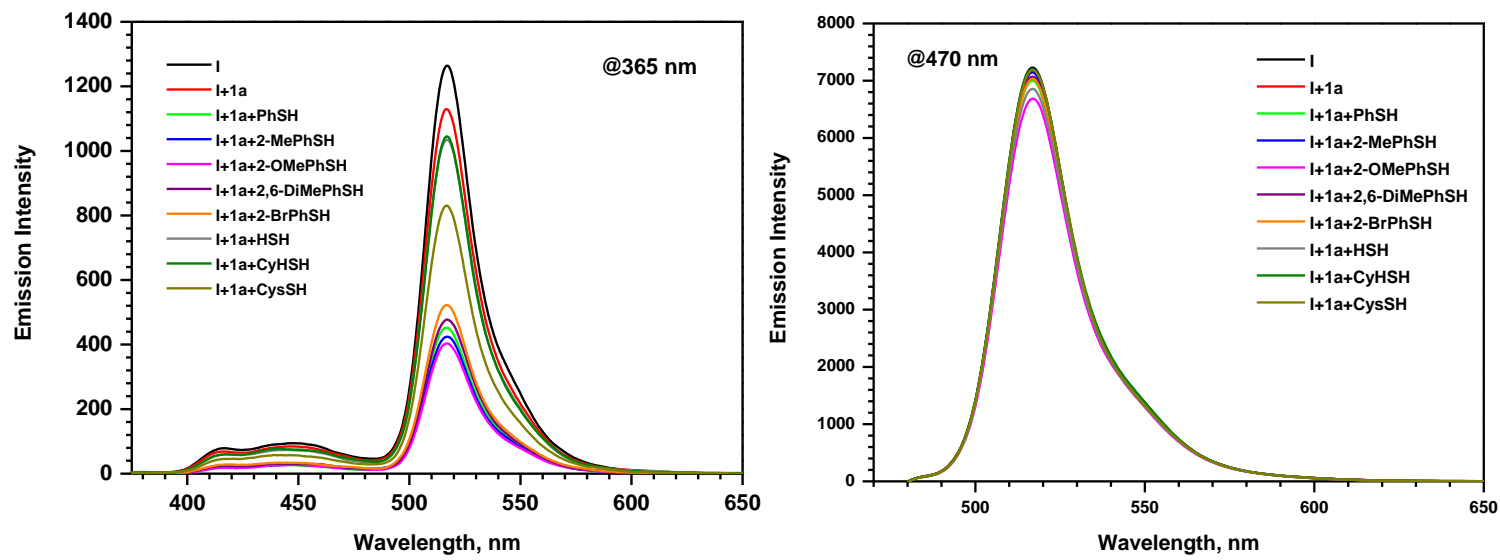

Figure S21. Emission spectra of I $(2 \mu \mathrm{M})$ with 1a $(8 \mu \mathrm{M})$ and different thiols $(8 \mu \mathrm{M})$ recorded in DMSO at different excitation wavelength.

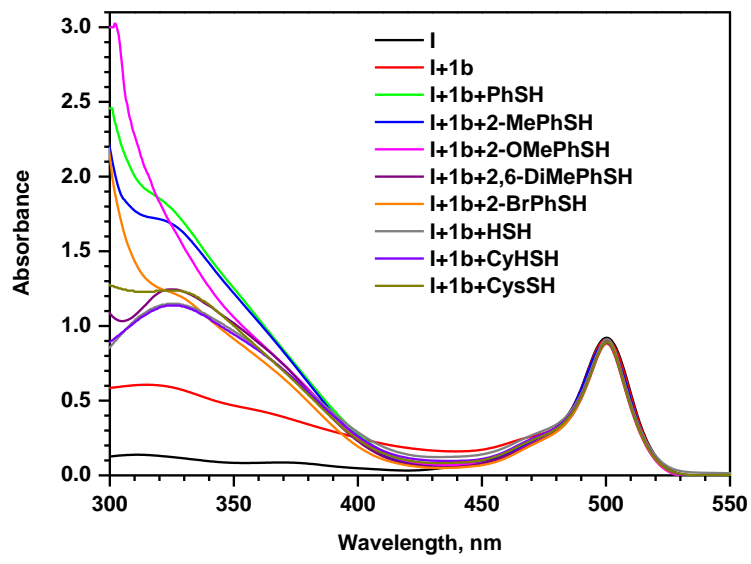

Figure S22. Absorption spectra of $\mathbf{I}(20 \mu \mathrm{M})$ with $\mathbf{1 b}(80 \mu \mathrm{M})$ and different thiols (80 $\mu \mathrm{M})$ recorded in DMSO. 

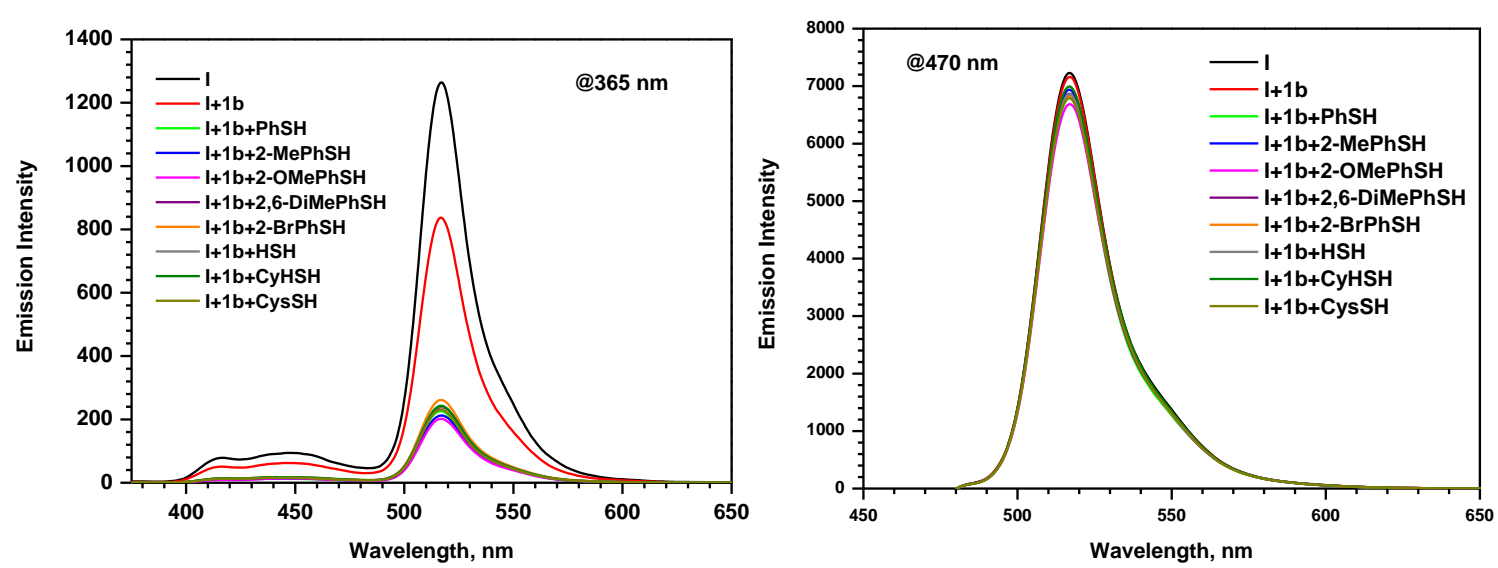

Figure S23. Emission spectra of $\mathbf{I}(2 \mu \mathrm{M})$ with $\mathbf{1 b}(8 \mu \mathrm{M})$ and different thiols $(8 \mu \mathrm{M})$ recorded in DMSO at different excitation wavelength.

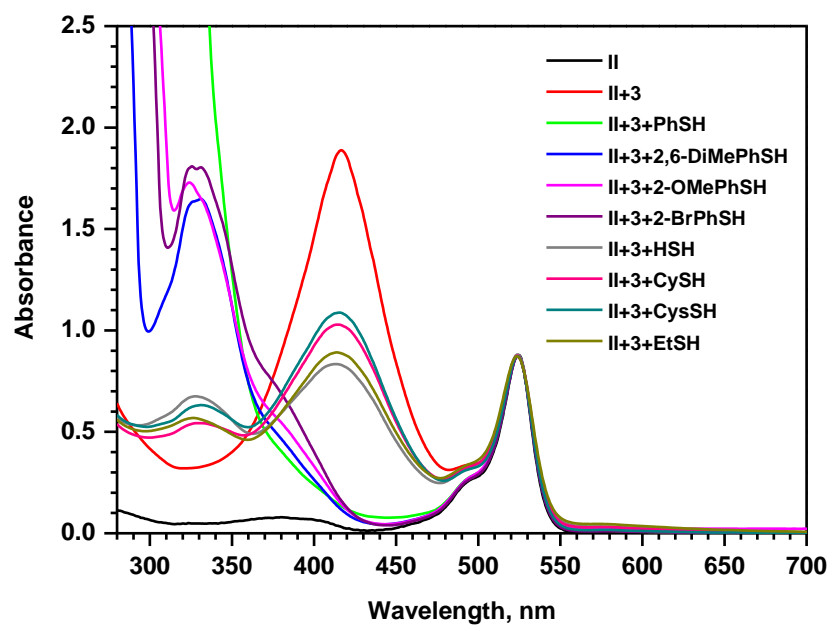

Figure S24. Absorption spectra of II $(10 \mu \mathrm{M})$ with $3(40 \mu \mathrm{M})$ and various thiols $(40 \mu \mathrm{M})$ in DMSO.
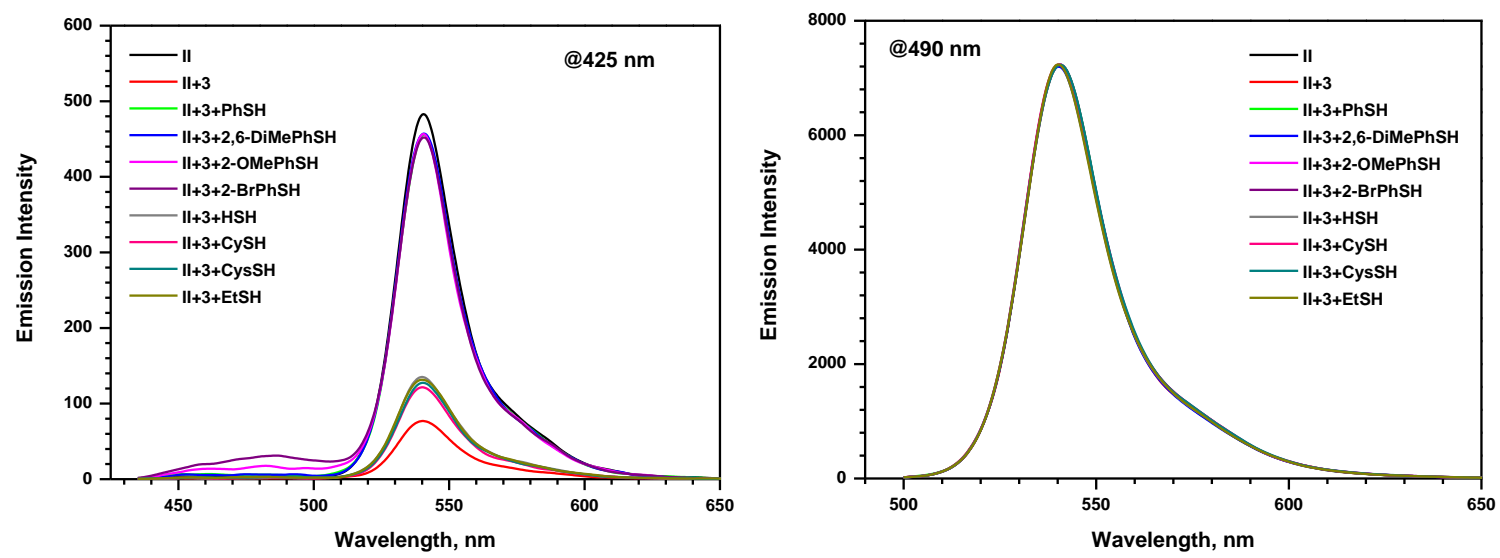

Figure S25. Emission spectra of II $(1 \mu \mathrm{M})$ with $3(4 \mu \mathrm{M})$ and various thiols $(4 \mu \mathrm{M})$ in DMSO at different excitation wavelengths. 


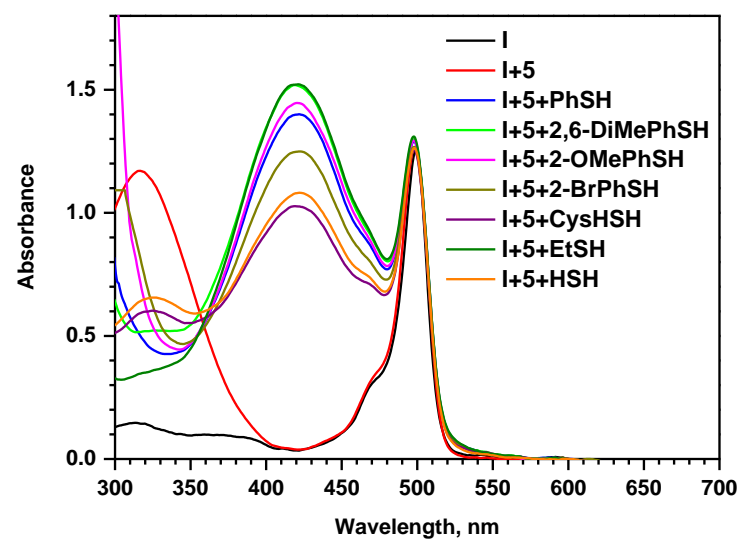

Figure S26. Absorption spectra of $\mathbf{I}(20 \mu \mathrm{M})$ with $\mathbf{5}(80 \mu \mathrm{M})$ and different thiols $(80 \mu \mathrm{M})$ recorded in EtOH:water (1:1).
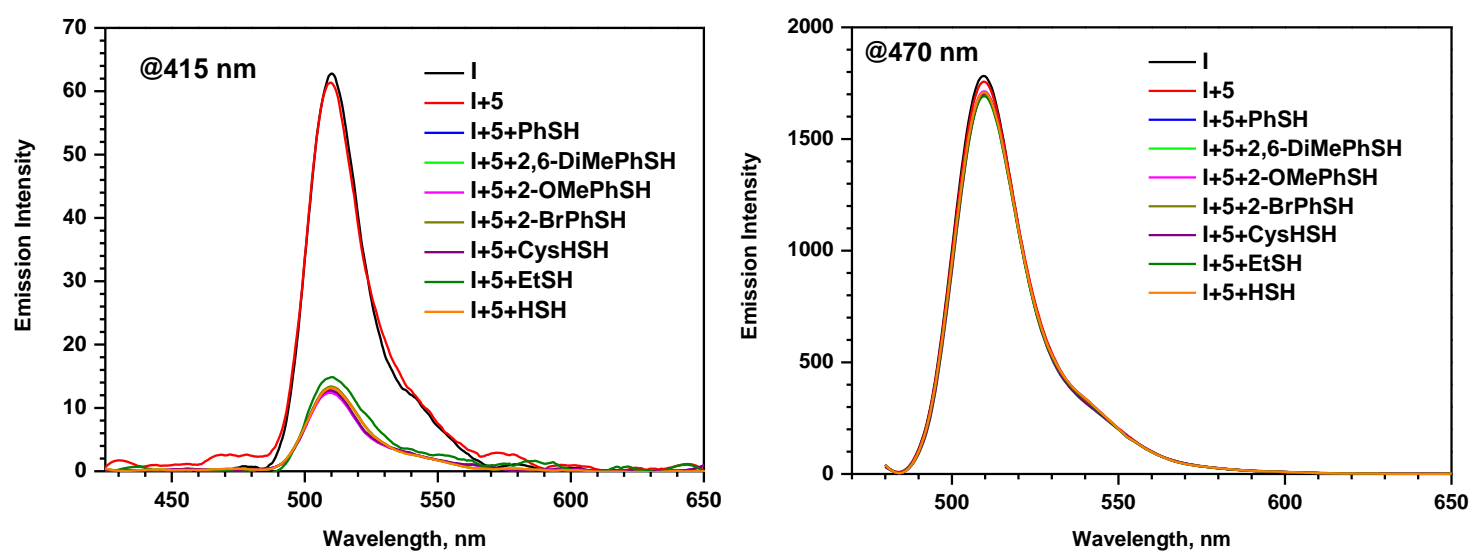

Figure S27. Emission spectra of $\mathbf{I}(0.1 \mu \mathrm{M})$ with $5(5 \mu \mathrm{M})$ and different thiols $(5 \mu \mathrm{M})$ recorded in EtOH:water (1:1). 

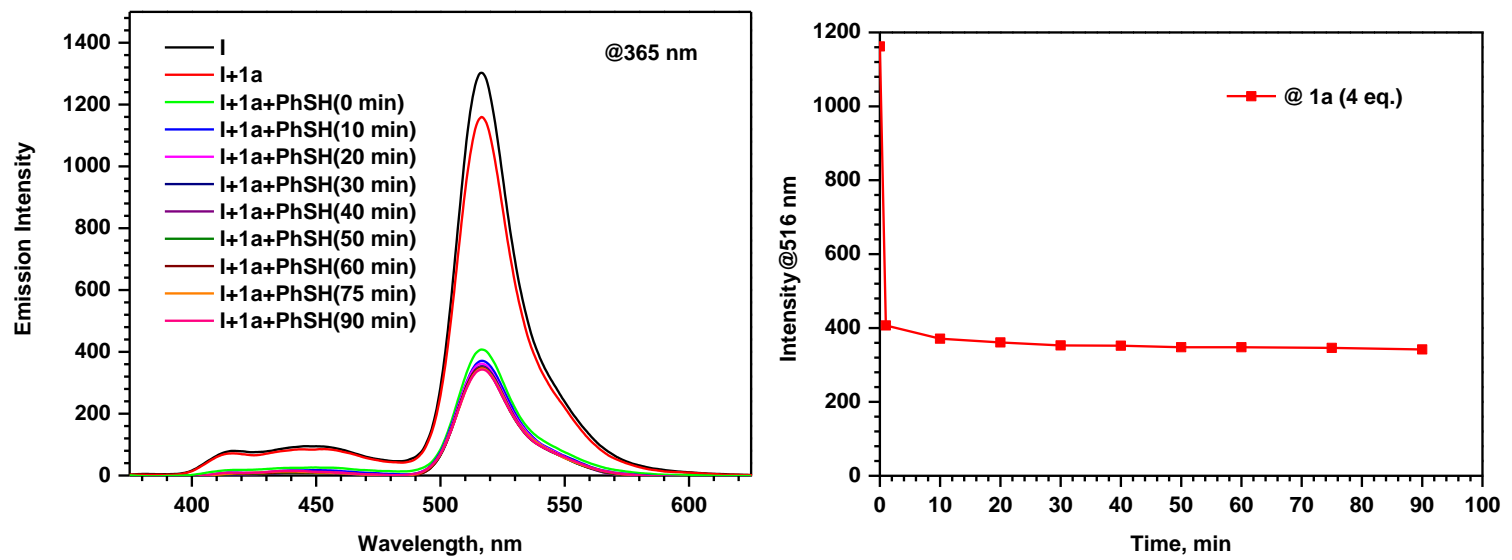

Figure S28. Emission spectra of I $(2 \mu \mathrm{M})$ with $1 \mathbf{a}(80 \mu \mathrm{M})$ and thiophenol $(80 \mu \mathrm{M})$ recorded in DMSO at different time interval.
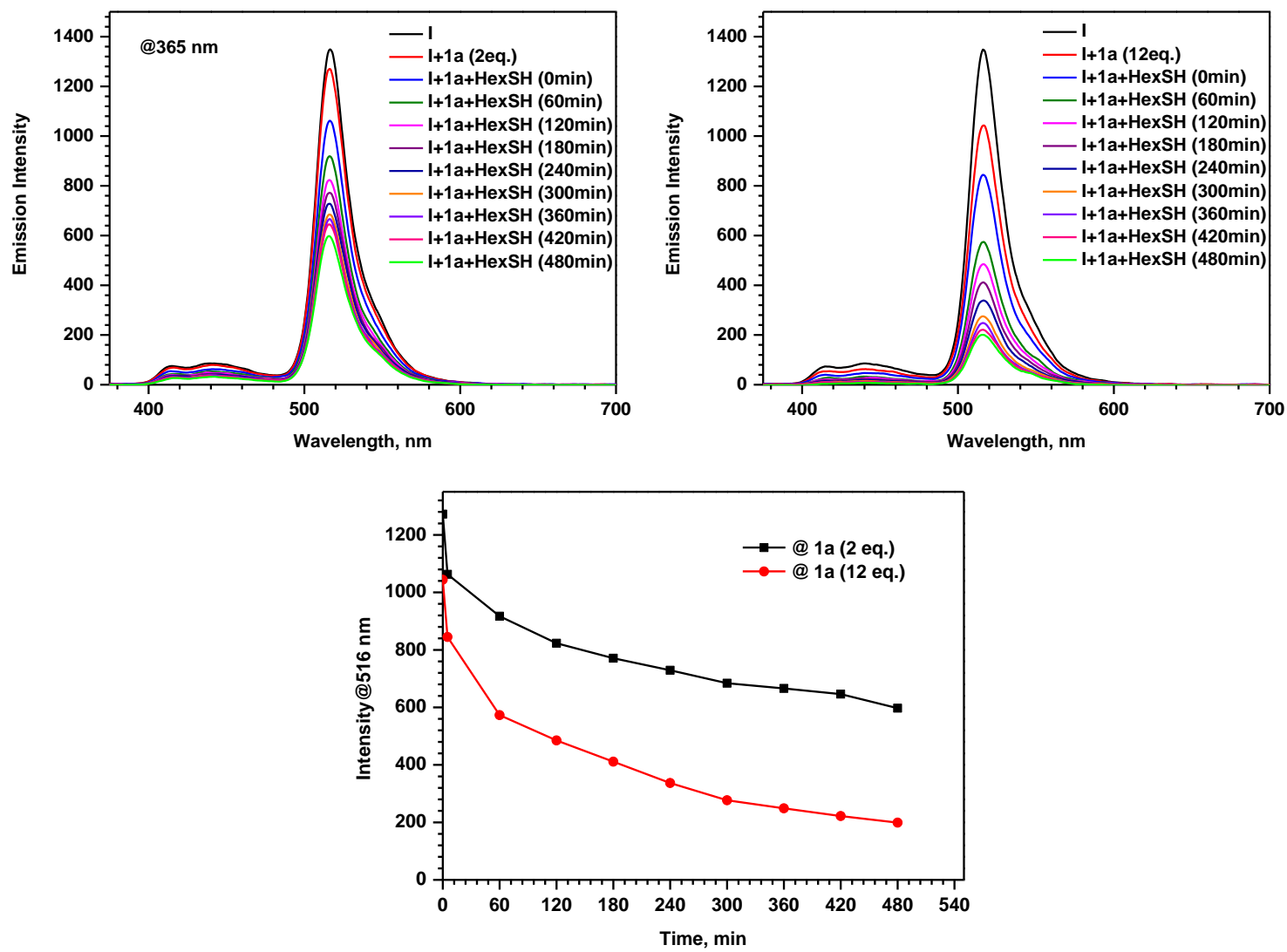

Figure S29. Emission spectra of $\mathbf{I}(2 \mu \mathrm{M})$ with different concentration of $\mathbf{1 a}$ and hexylthiol (HexSH) recorded in DMSO at different time interval. 


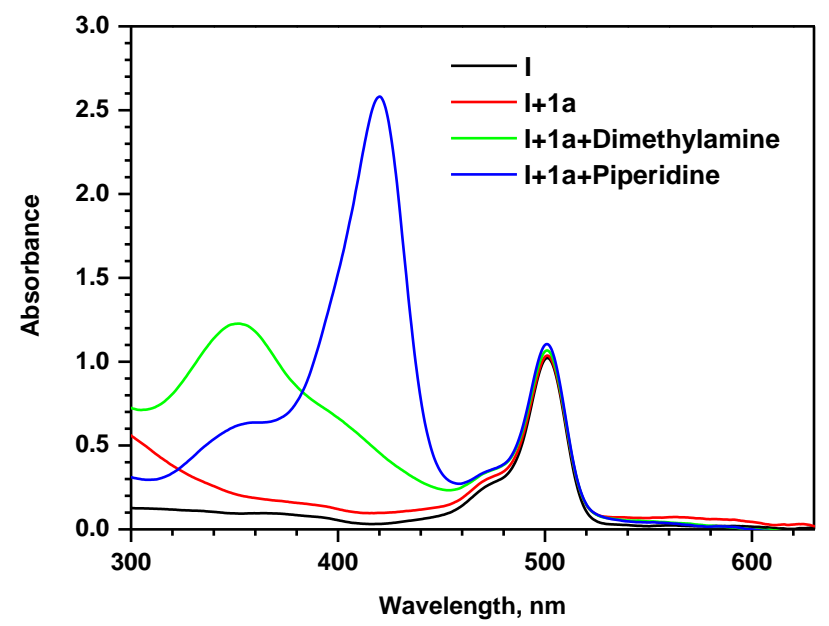

Figure S30. Absorption spectra of $\mathbf{I}(20 \mu \mathrm{M})$ with 1a $(80 \mu \mathrm{M})$ and different secondary amines $(80 \mu \mathrm{M})$ recorded in DMSO.
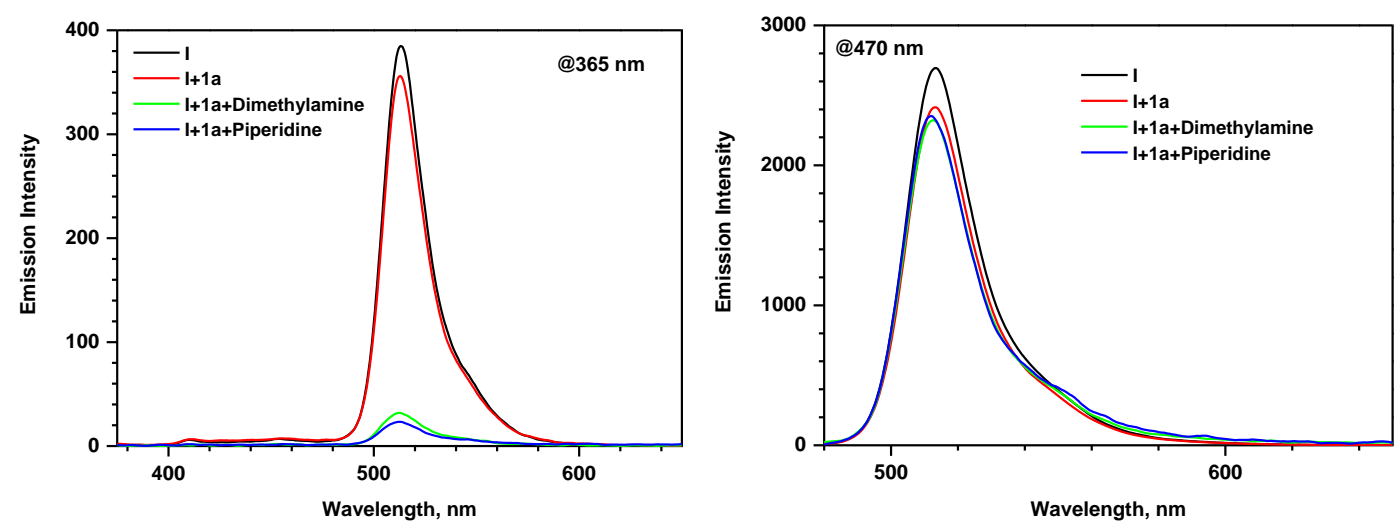

Figure S31. Emission spectra of $\mathbf{I}(1 \mu \mathrm{M})$ with $1 \mathbf{a}(4 \mu \mathrm{M})$ and different secondary amines $(4 \mu \mathrm{M})$ recorded in DMSO.

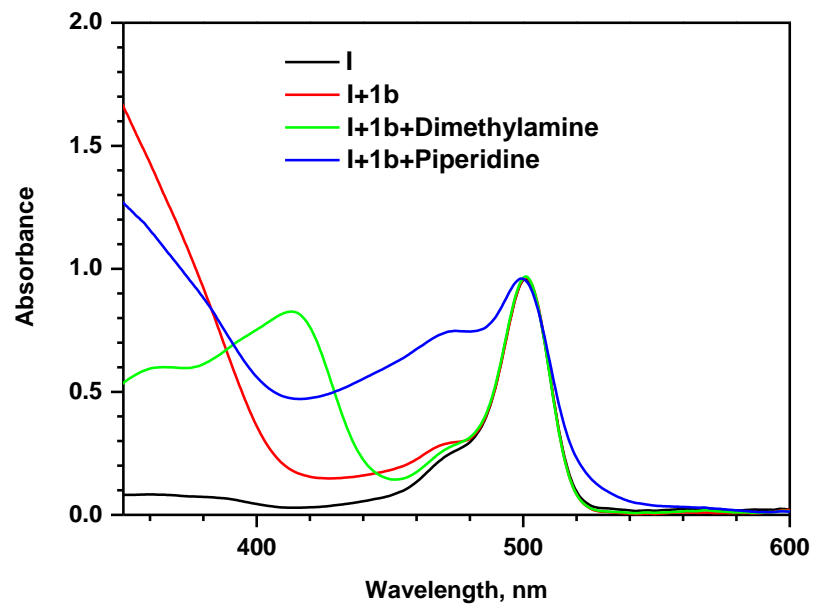

Figure S32. Absorption spectra of $\mathbf{I}(20 \mu \mathrm{M})$ with $\mathbf{1 b}(80 \mu \mathrm{M})$ and different secondary amines $(80 \mu \mathrm{M})$ recorded in DMSO. 

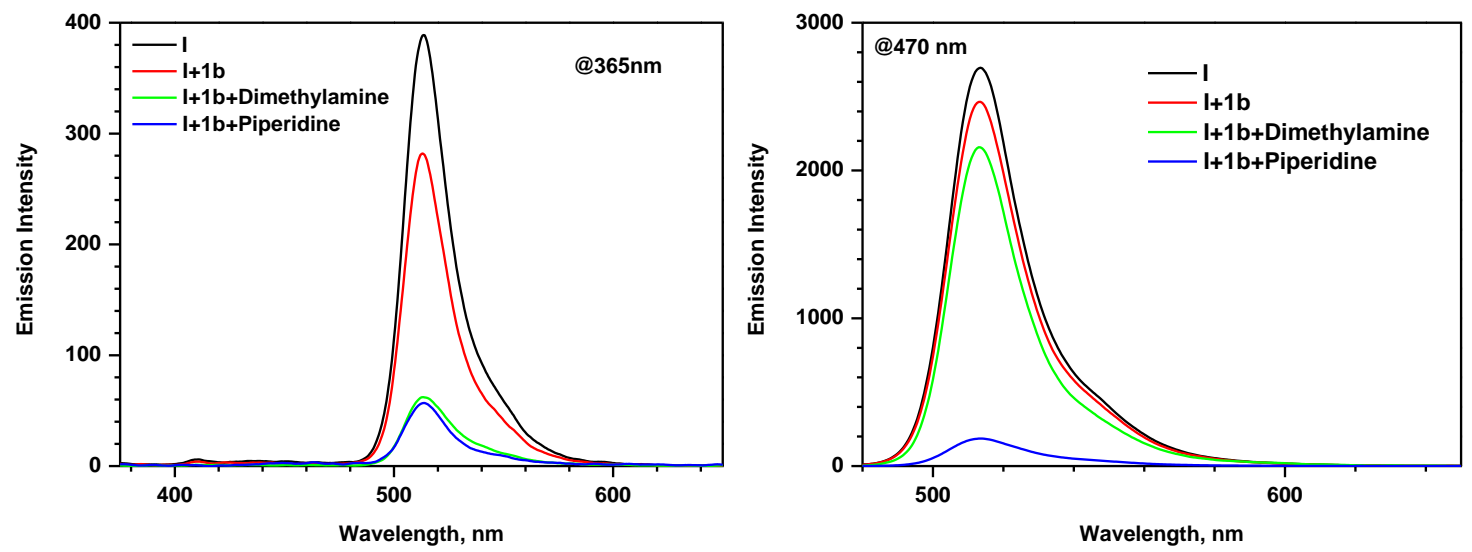

Figure S33. Emission spectra of $\mathbf{I}(1 \mu \mathrm{M})$ with $\mathbf{1 b}(4 \mu \mathrm{M})$ and different secondary amines $(4 \mu \mathrm{M})$ recorded in DMSO.
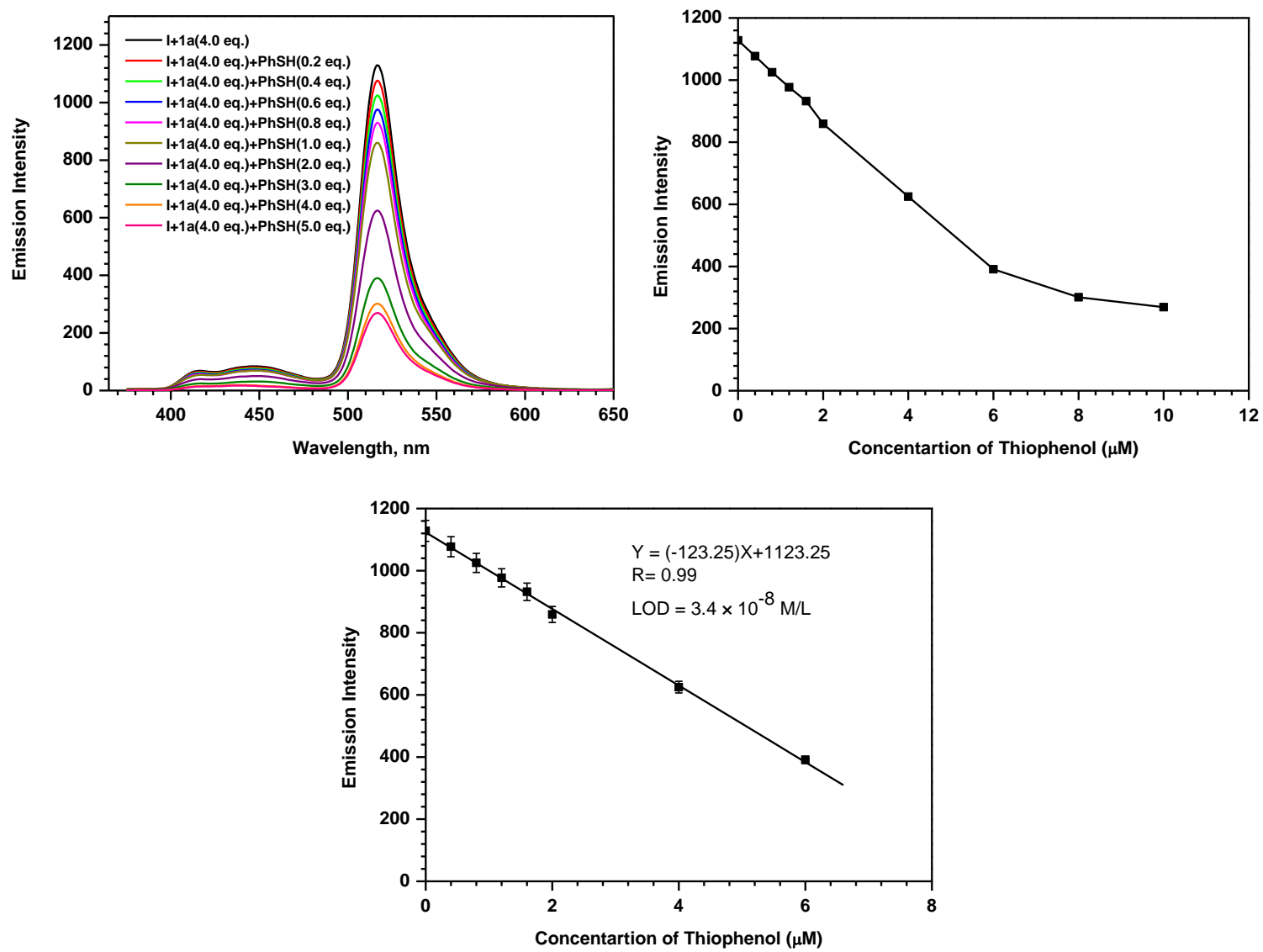

Figure S34. Emission spectra of I $(2 \mu \mathrm{M})$ with $1 \mathbf{a}(8 \mu \mathrm{M})$ and different concentration of thiophenol recorded in DMSO. 

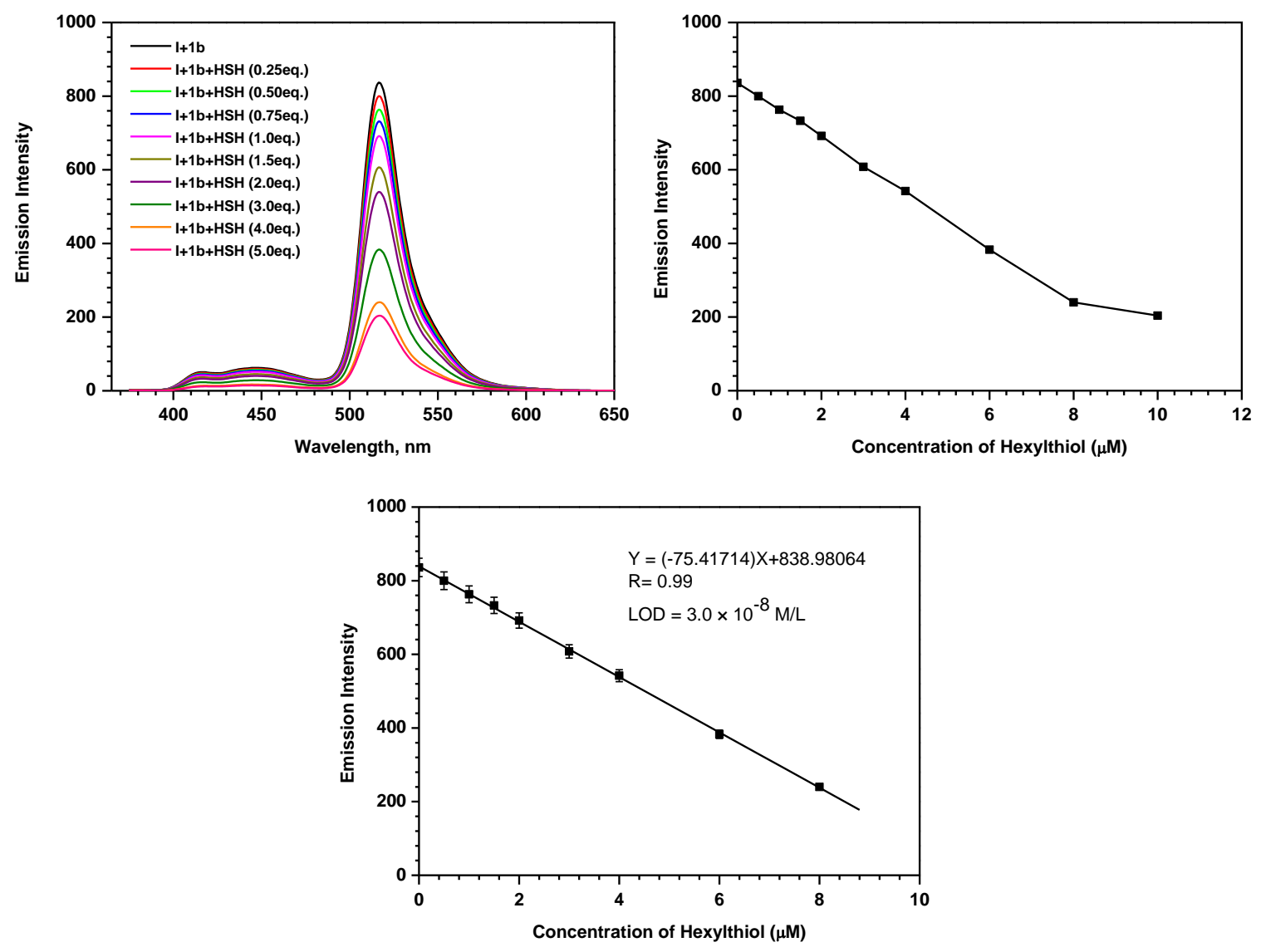

Figure S35. Emission spectra of $\mathbf{I}(2 \mu \mathrm{M})$ with $\mathbf{1 b}(8 \mu \mathrm{M})$ and different concentration of hexylthiol (HSH) recorded in DMSO. 

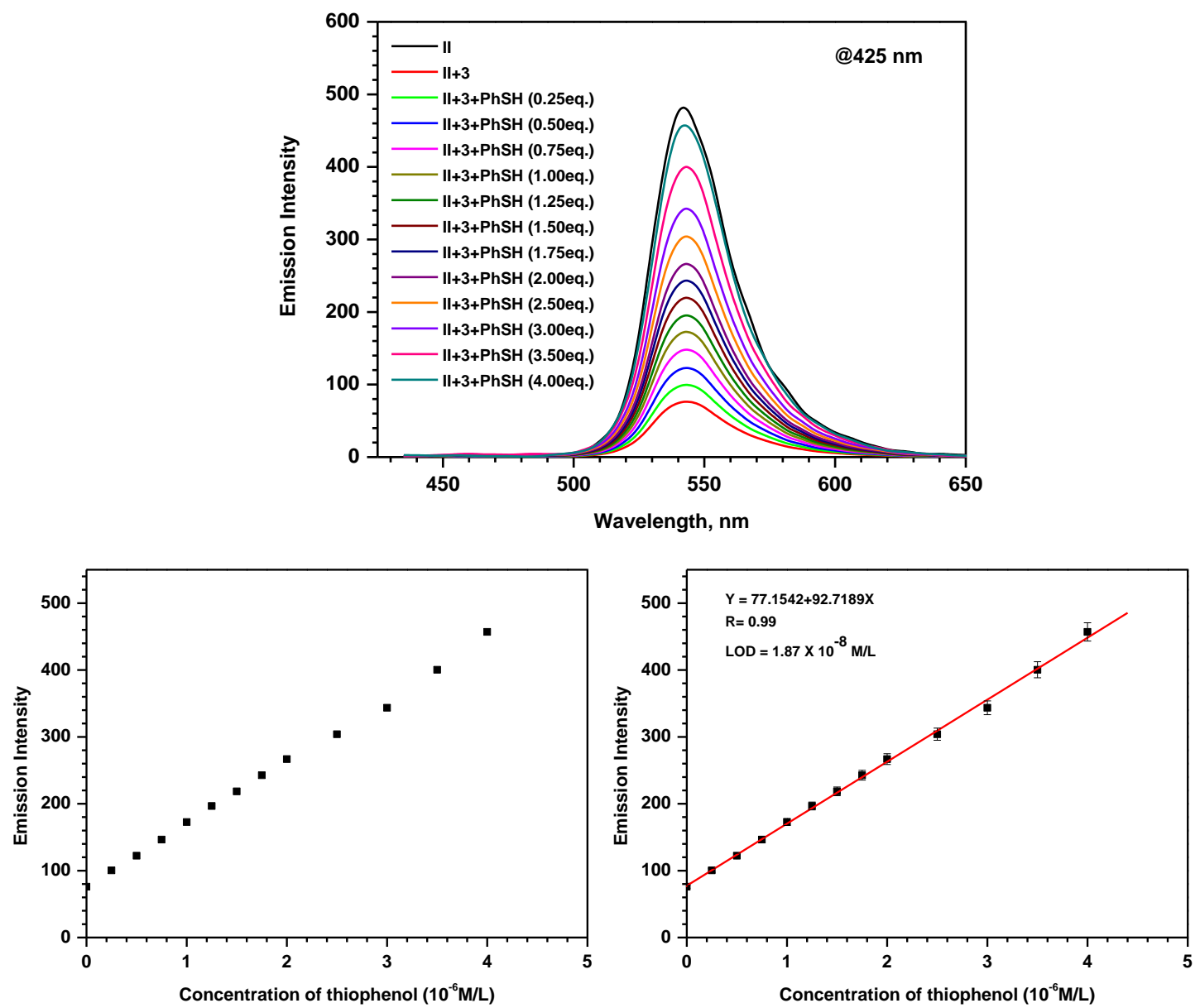

Figure S36. Emission spectra of II $(1 \mu \mathrm{M})$ with $\mathbf{3}(4 \mu \mathrm{M})$ and different concentration of thiophenol in DMSO. 

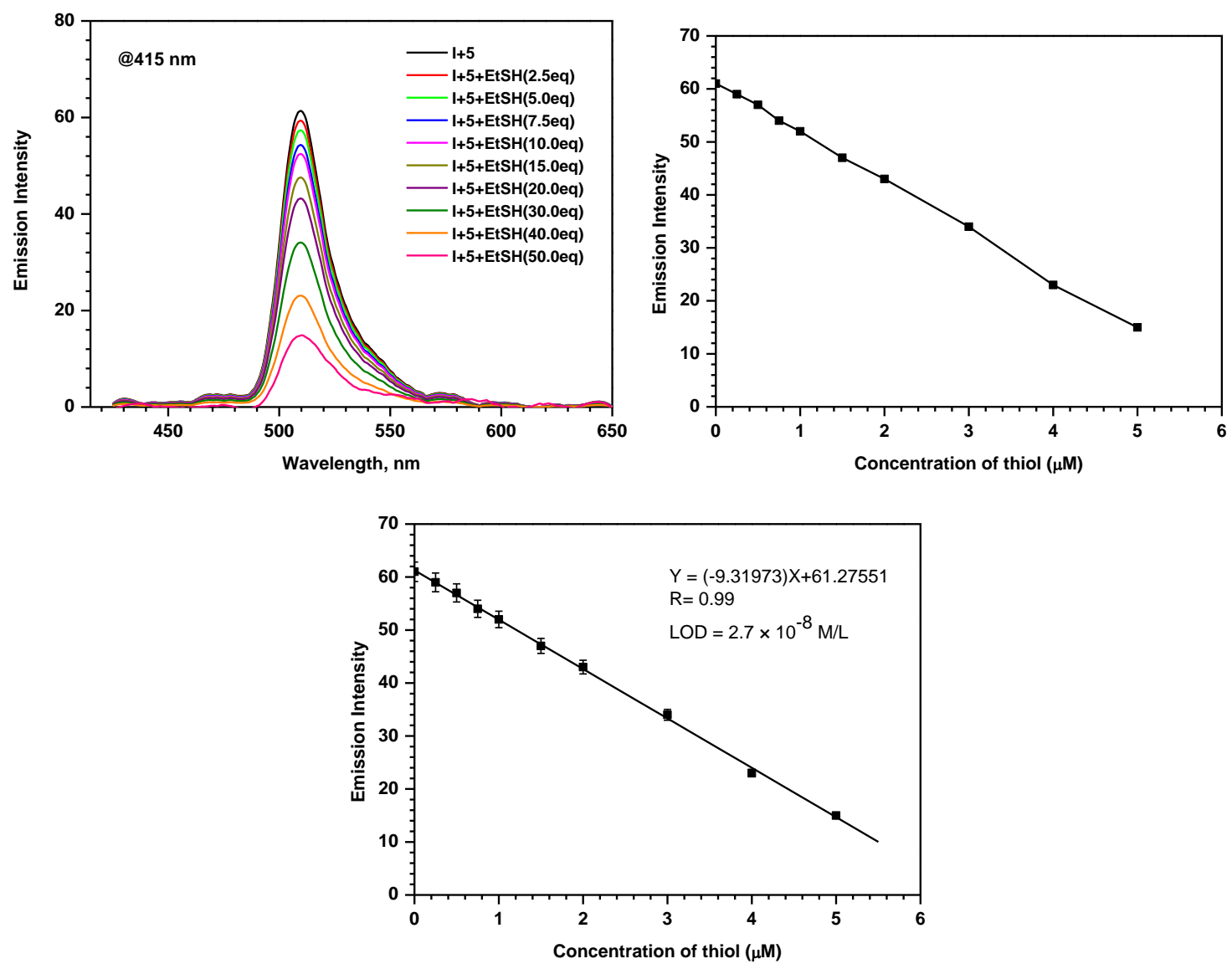

Figure S37. Emission spectra of $\mathbf{I}(0.1 \mu \mathrm{M})$ with $\mathbf{5}(5 \mu \mathrm{M})$ and different concentration of 2-Mercaptoethanol (EtSH) recorded in EtOH:water (1:1).

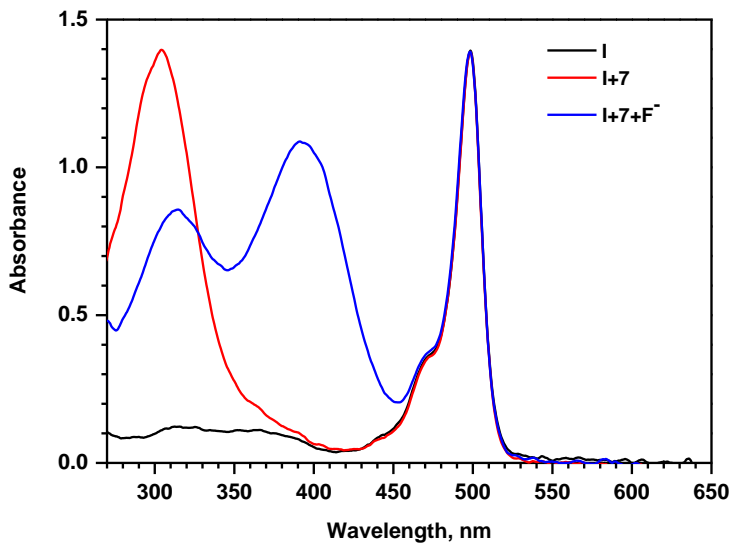

Figure S38. Absorption spectra of $\mathbf{I}(10 \mu \mathrm{M})$ with $7(500 \mu \mathrm{M})$ and fluoride $(100 \mu \mathrm{M})$ in $\mathrm{MeOH}: \mathrm{H}_{2} \mathrm{O}(9: 1)$ in 50 min. 

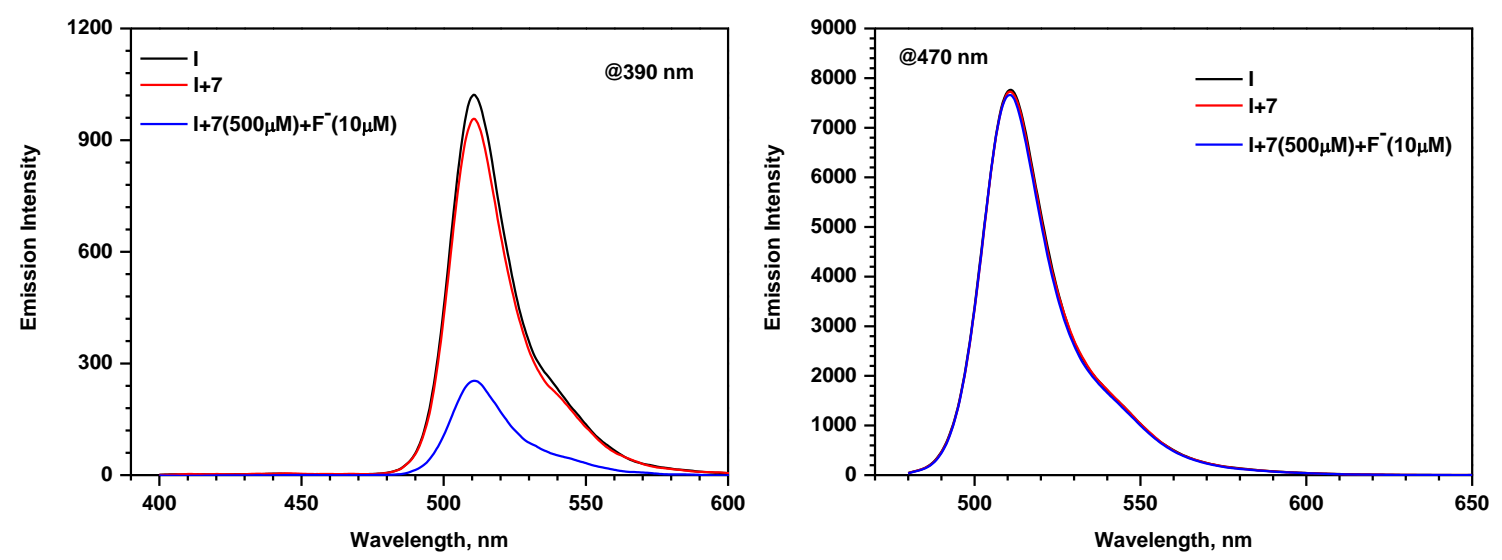

Figure S39. Emission spectra of $\mathbf{I}(10 \mu \mathrm{M})$ with $7(500 \mu \mathrm{M})$ and fluoride $(10 \mu \mathrm{M})$ in $\mathrm{MeOH}: \mathrm{H}_{2} \mathrm{O}(9: 1)$ in $50 \mathrm{~min}$.
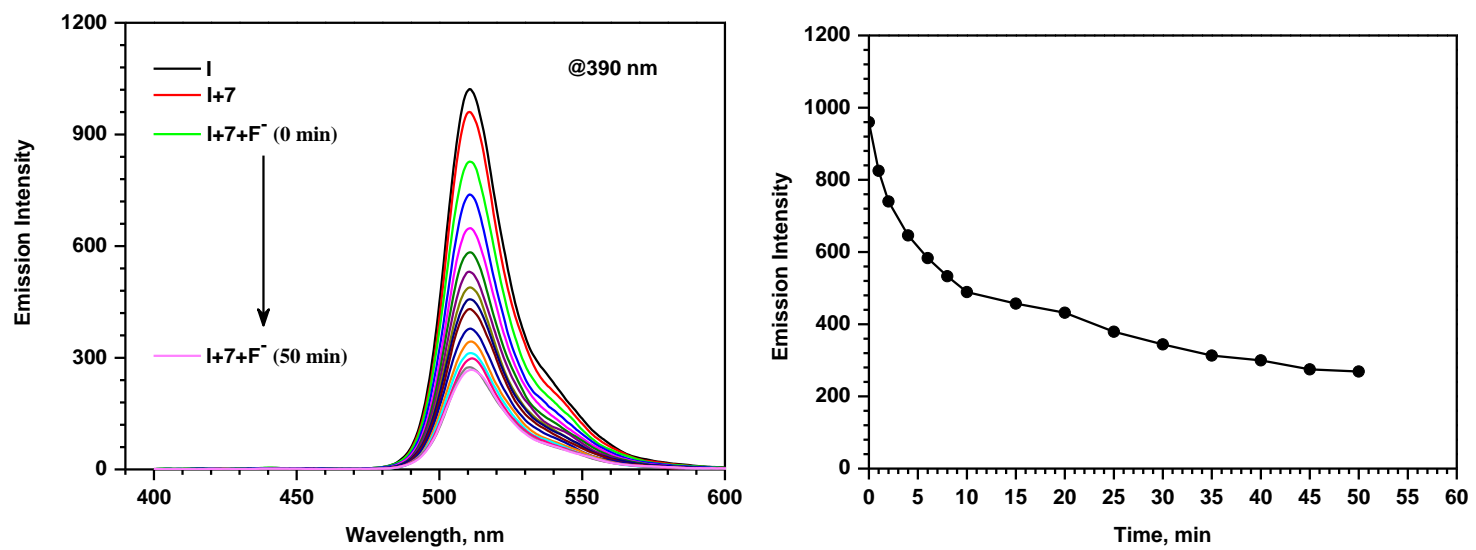

Figure S40. Emission spectra of $\mathbf{I}(10 \mu \mathrm{M})$ with $7(500 \mu \mathrm{M})$ and fluoride $(10 \mu \mathrm{M})$ in $\mathrm{MeOH}: \mathrm{H}_{2} \mathrm{O}(9: 1)$ at different time interval.
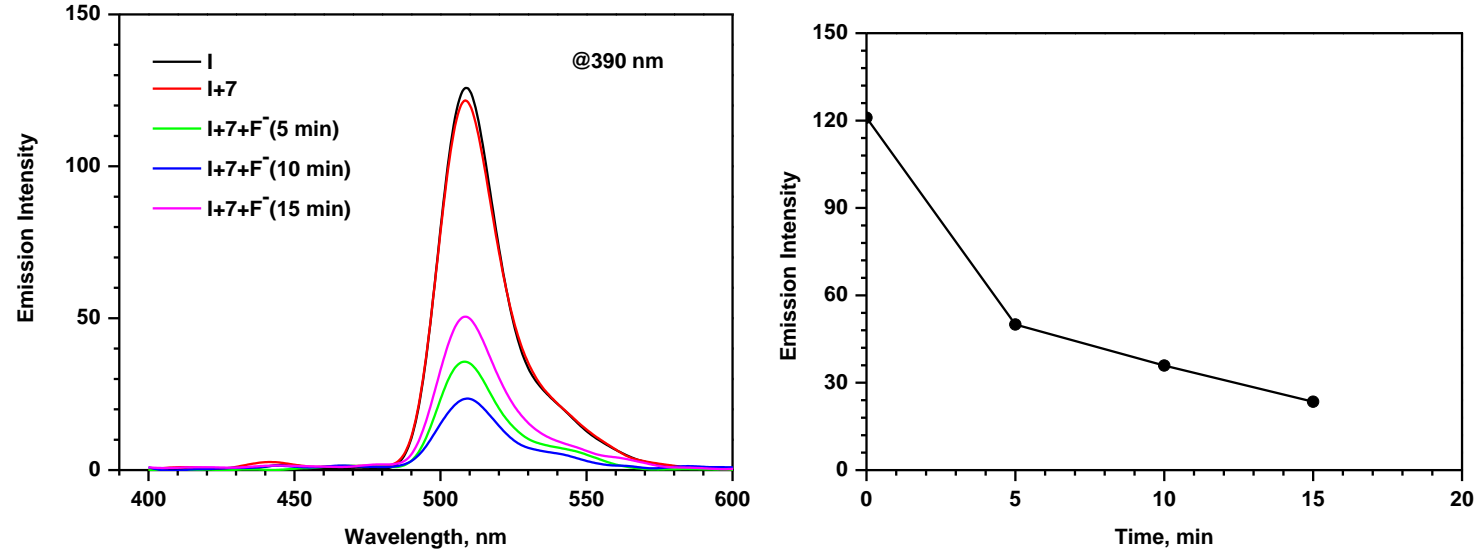

Figure S41. Emission spectra of $\mathbf{I}(1 \mu \mathrm{M})$ with $7(500 \mu \mathrm{M})$ and fluoride $(10 \mu \mathrm{M})$ in $\mathrm{MeOH}: \mathrm{H}_{2} \mathrm{O}(9: 1)$ at different time interval. 

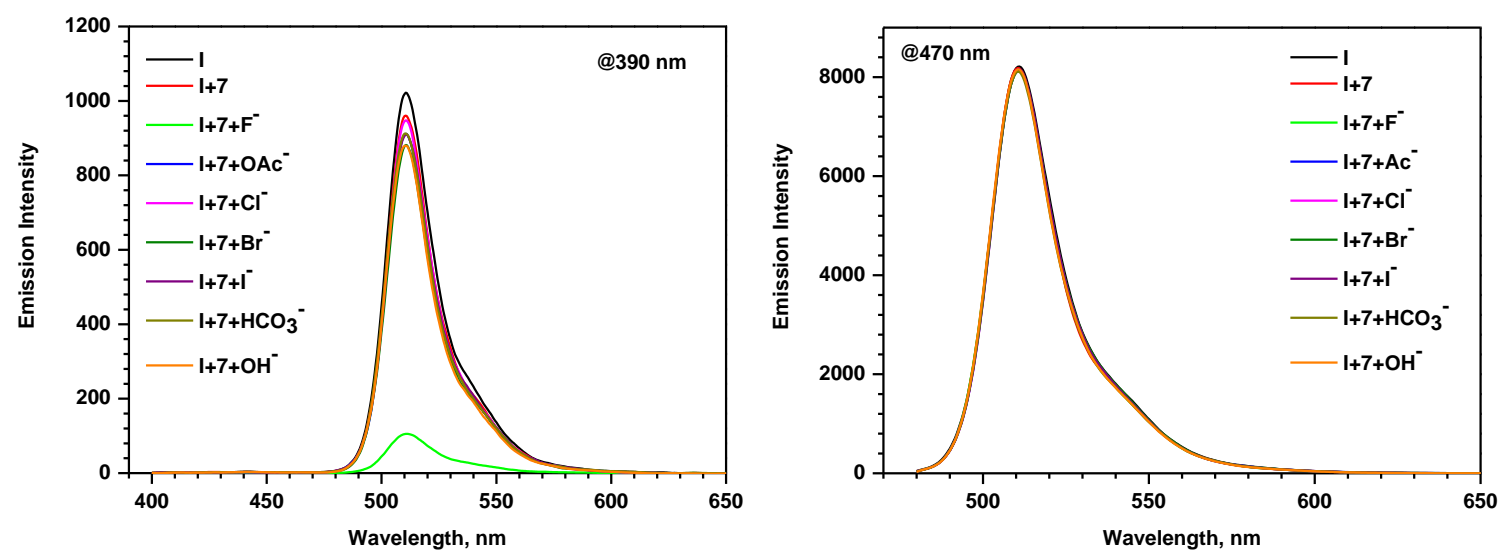

Figure S42. Emission spectra of $\mathbf{I}(10 \mu \mathrm{M})$ with $7(500 \mu \mathrm{M})$ and various anions (100 $\mu \mathrm{M})$ in $\mathrm{MeOH}: \mathrm{H}_{2} \mathrm{O}(9: 1)$ (Incubation time $50 \mathrm{~min}$ ).
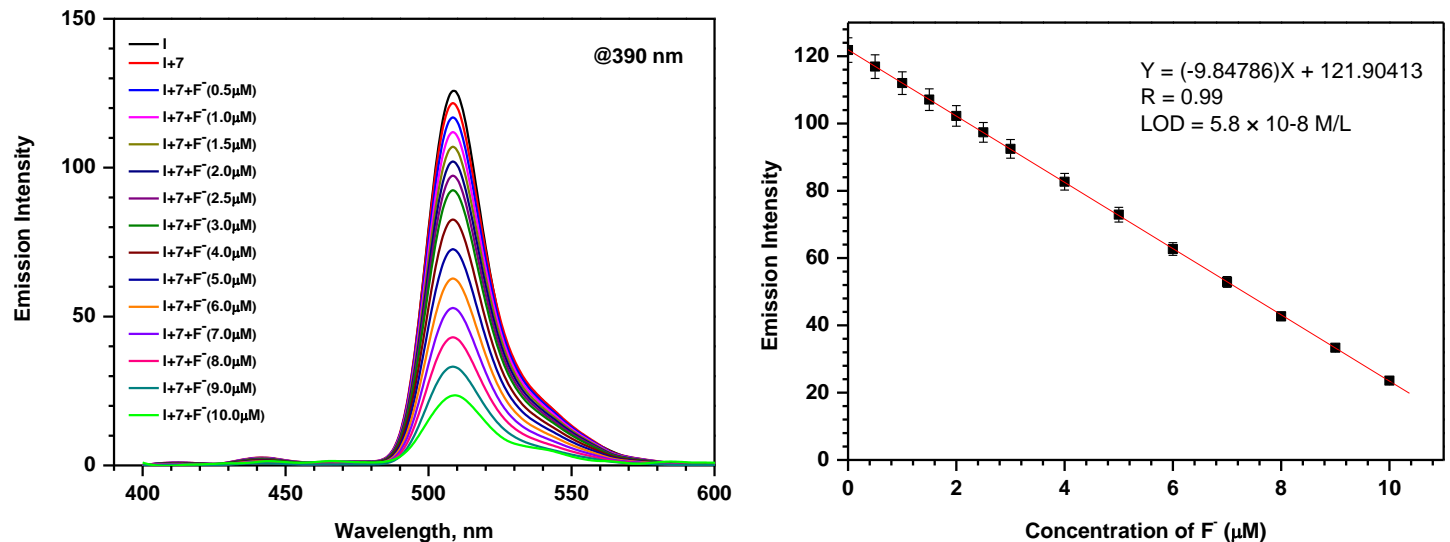

Figure S43. Emission spectra of $\mathbf{I}(1 \mu \mathrm{M})$ with $7(500 \mu \mathrm{M})$ and different concentration of Fluoride in $\mathrm{MeOH}: \mathrm{H}_{2} \mathrm{O}(9: 1)$.

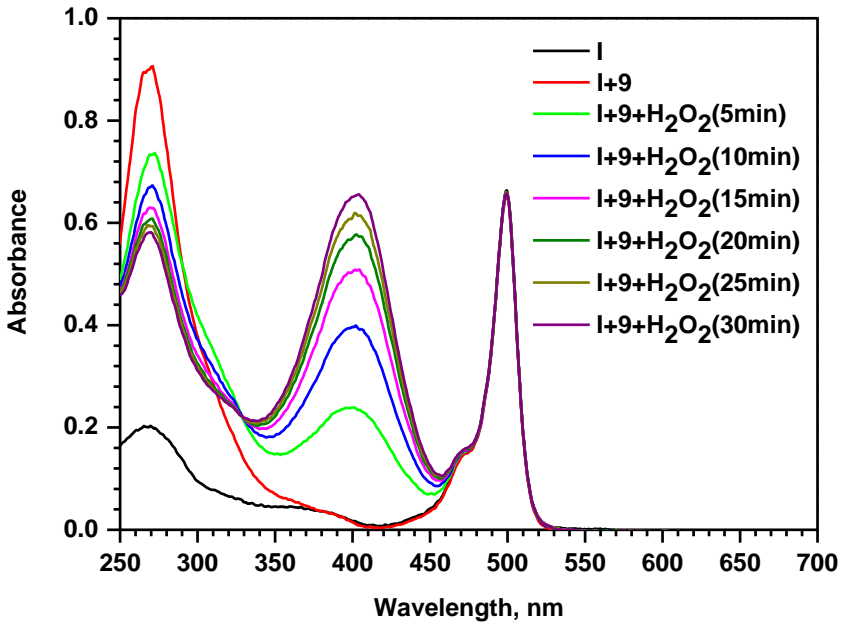

Figure S44. Absorption spectra of $\mathbf{I}(10 \mu \mathrm{M})$ with $9(50 \mu \mathrm{M})$ and $\mathrm{H}_{2} \mathrm{O}_{2}(10 \mu \mathrm{M})$ in Ethanol:water (9:1) using carbonate buffer $\mathrm{pH} 9.2$. 

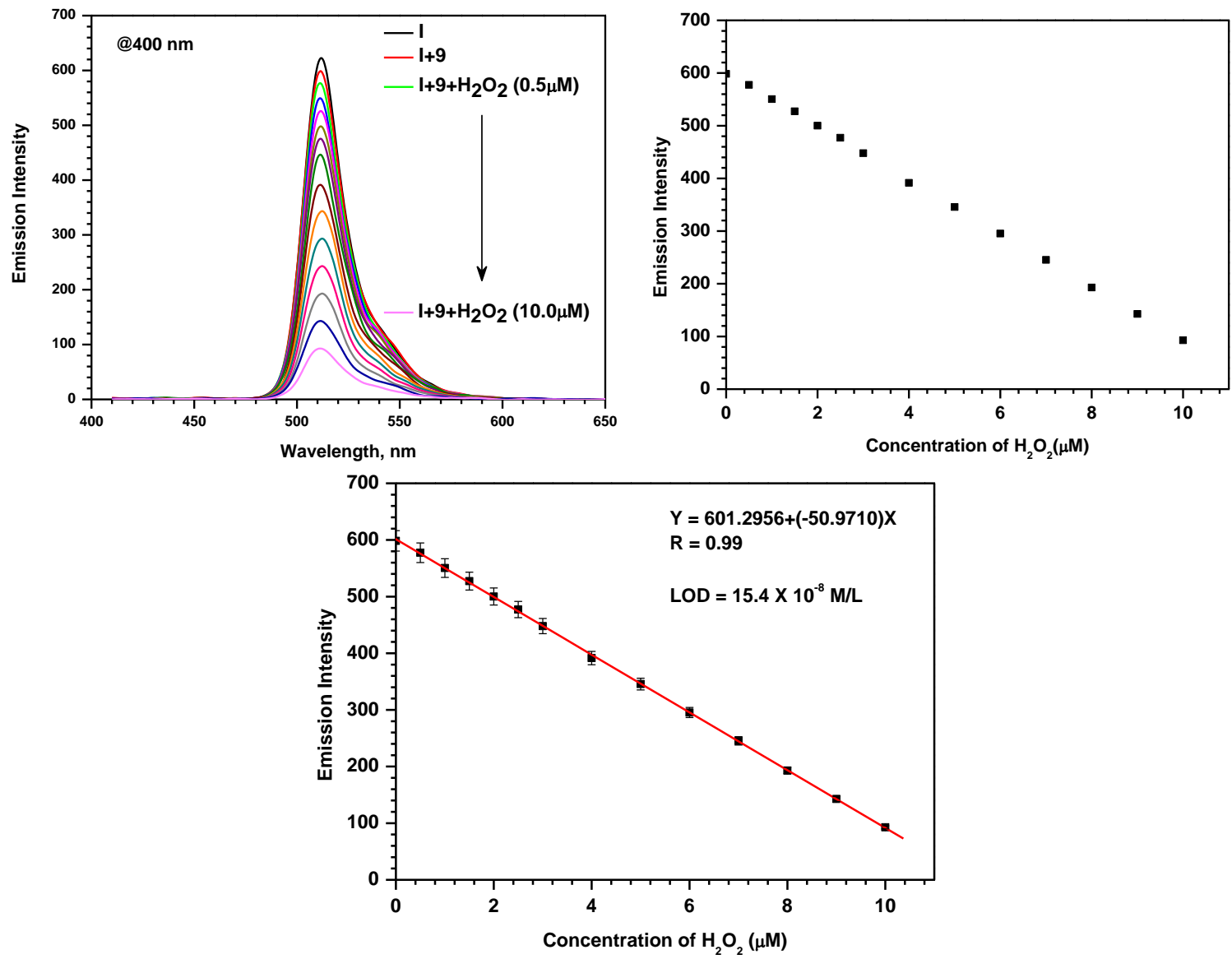

Figure S45. Emission spectra of I $(10 \mu \mathrm{M})$ with $9(50 \mu \mathrm{M})(9: 1)$ with different concentration of $\mathrm{H}_{2} \mathrm{O}_{2}$ in Ethanol:water using carbonate buffer $\mathrm{pH}$ 9.2.
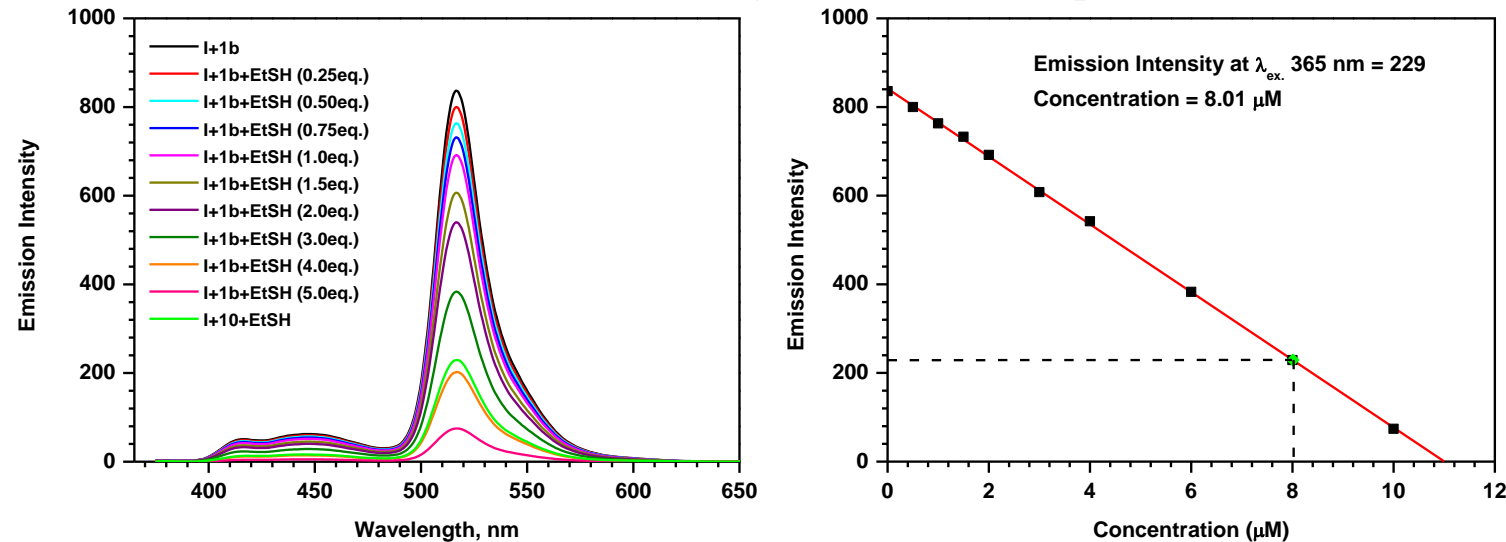

Figure S46. Emission spectra and the calibration curve to determine the concentration of product formed after the reaction of $\mathbf{1 0}$ with 2-mercapto ethanol (EtSH) in DMSO. 


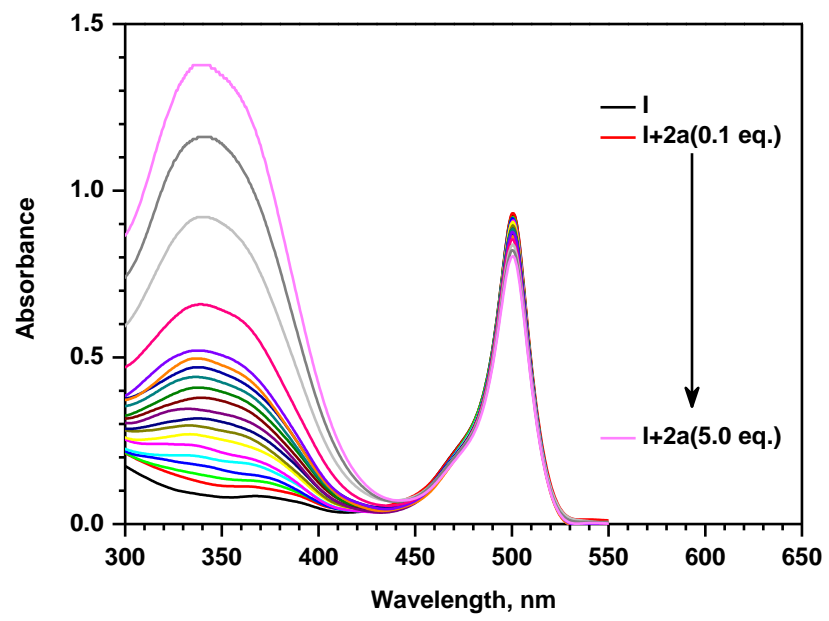

Figure S47. Absorption spectra of $\mathbf{I}(20 \mu \mathrm{M})$ before and after addition of $\mathbf{2 a}$ recorded in DMSO.

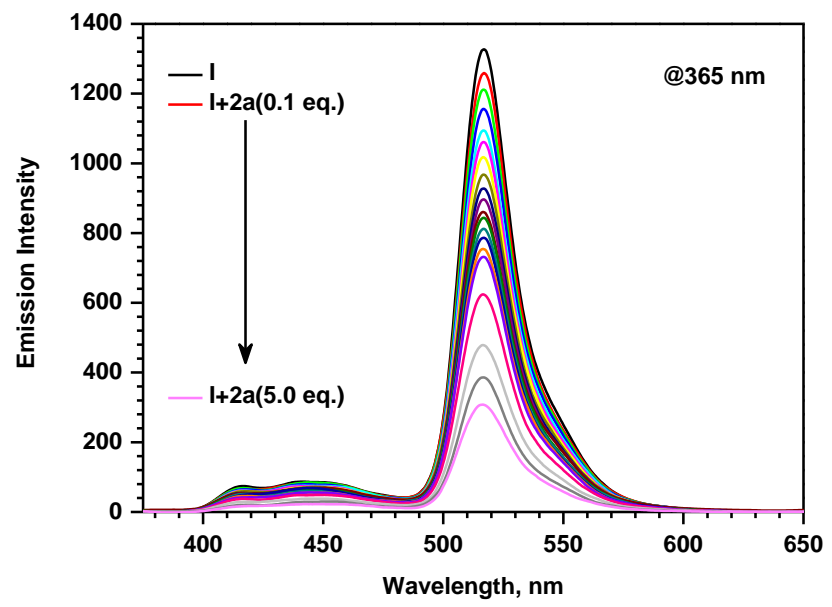

Figure S48. Emission spectra of I $(2 \mu \mathrm{M})$ before and after addition of $\mathbf{2 a}$ recorded in DMSO.

\section{References}

1. Brasselet, S.; Cherioux, F.; Audebert, P.; Zyss J. Chem. Mater. 1999, 11, 1915-1920.

2. Jiang, W.; Fu, Q.; Fan, H.; Ho, J.; Wang, W. Angew. Chem. Int. Ed. 2007, 46, 84458448 